Article

\title{
Do the Different Exergy Accounting Methodologies Provide Consistent or Contradictory Results? A Case Study with the Portuguese Agricultural, Forestry and Fisheries Sector
}

\author{
Ricardo Manso *, Tânia Sousa and Tiago Domingos \\ Marine, Environment and Technology Centre-MARETEC, Department of Mechanical Engineering, \\ Instituto Superior Técnico, Universidade de Lisboa, Avenida Rovisco Pais, 1, 1049-001 Lisbon, Portugal; \\ taniasousa@tecnico.ulisboa.pt (T.S.); tdomingos@tecnico.ulisboa.pt (T.D.) \\ * Correspondence: ricardo.manso@tecnico.ulisboa.pt; Tel.: +351-968972498
}

Received: 22 June 2017; Accepted: 11 August 2017; Published: 17 August 2017

\begin{abstract}
Three exergy accounting approaches are used to evaluate exergy efficiency: the Energy Resources Exergy Accounting (EREA), the Natural Resources' Exergy Accounting (NREA) and the Extended Exergy Accounting (EEA). To test the consistency of the results provided by these methodologies, we apply them to evaluate the Portuguese agricultural, forestry and fisheries (AFF) sector, from 2000 to 2012. EREA shows an increase of 30\% in the efficiency of the Portuguese AFF sector, while NREA and EEA methodologies increases of $27 \%$ and $43 \%$, respectively. Although the results are consistent for the AFF sector, the same does not happen in the fisheries subsector, whose exergetic efficiency increases $14 \%$ with the EREA but decreases $42 \%$ with the NREA approach. The ratio of output to useful exergy reveals that a better thermodynamic efficiency is not translated into a higher energy service efficiency because fishing vessels have to travel more to get the same fish. Thus, results provided by the EREA and NREA approaches are complementary and both are needed to provide a realistic picture of exergy efficiency. On the other hand, results obtained by the EEA approach are dominated by capital and environmental impacts, revealing the disproportionality between material and immaterial inputs in this methodology.
\end{abstract}

Keywords: exergy; extended exergy accounting; efficiency; environmental assessment; agriculture

\section{Introduction}

Sustainable development is the desirable long term goal of bringing humankind to a compromise between its welfare and the protection of our planet. According to Pezzey [1] "A temptation when writing on 'defining sustainability' is to try to distill, from the myriad debates, a single definition which commands the widest possible academic consent. However, several years spent in fitful pursuit of this goal have finally persuaded me that it is an alchemist's dream, no more likely to be found than an elixir to prolong life indefinitely". Still, the most consensual definition of sustainable development is provided by the Brundtland Report [2]: "Sustainable development is development that meets the needs of the present without compromising the ability of future generations to meet their own needs".

The sustainability of society is critically dependent on the agricultural, forestry and fisheries (AFF) sector because all mass and energy flows that maintain our society come either directly from the environment or from the energy and mass surpluses obtained in this sector and the resource extraction and energy transformation sectors. The AFF sector provides all the food, feed and fiber and is also a major source of renewable energy resources. According to Committee on Twenty-First Century Systems Agriculture [3], the sustainability of the AFF sector should take into account the environmental, social and economic dimensions: 
- Satisfy human food, feed, and fiber needs, and contribute to biofuels needs.

- Enhance environmental quality and the resource base.

- Sustain the economic viability of agriculture.

- Enhance the quality of life for farmers, farm workers, and society as a whole.

Several efforts have been made in measuring the sustainability of the AFF sector, but the focus is, in most cases, only on one of the pillars of sustainability. The complementary research of both social and economic sustainability dimensions with efficiency and environmental extraction is both scarce and complex since no common unit is easily found and accepted. Also, success in one dimension does not imply the same for the others. The economic viability of an agricultural sector is not directly correlated with the environmental efficiency of the same sector nor the wellbeing of farmers.

Exergy analysis is an assessment methodology that has been used to account for efficiency at several scales, which can be society as a whole, economic sectors or industries. The term efficiency usually reflects a narrow approach that considers only one type of output and input flows. However, an efficiency measure of the AFF sector that would take into account several types of flows, such as the extraction from the environment of renewable and non-renewable resources, undesired output flows such as waste and pollution and the capital and labour flows involved, could present useful insights about its sustainability. Further assessment of other aspects, such as the economic viability of agriculture or the quality of life of farmers, would still be needed for a complete evaluation of sustainability.

Exergy is the maximum amount of work that can be obtained from a system (a resource or a flow) when it is brought to equilibrium with the surrounding environment through a reversible process [4]. One of the key properties of exergy is that it allows the conversion of all inputs and outputs of a process into a common unit, allowing comparisons otherwise impossible.

The first methodology to quantify exergy flows was the energy resources' exergy accounting (EREA) methodology that started with energy carriers only [5]. Later, natural resources were included [6] in the natural resources' exergy accounting (NREA) methodology and more recently capital, labour and environmental externalities [7] in the extended exergy accounting (EEA) methodology.

EREA is an input assessment method that measures the exergy embedded (or intrinsic) in the energy carriers used by the transformation devices (inputs) and the useful exergy (outputs) (Figure 1). With EREA is possible to determine how well the system converts the final exergy to useful work from the available energy carriers and transformation devices; this knowledge can then be used to propose measurements to improve the efficiency of the system.

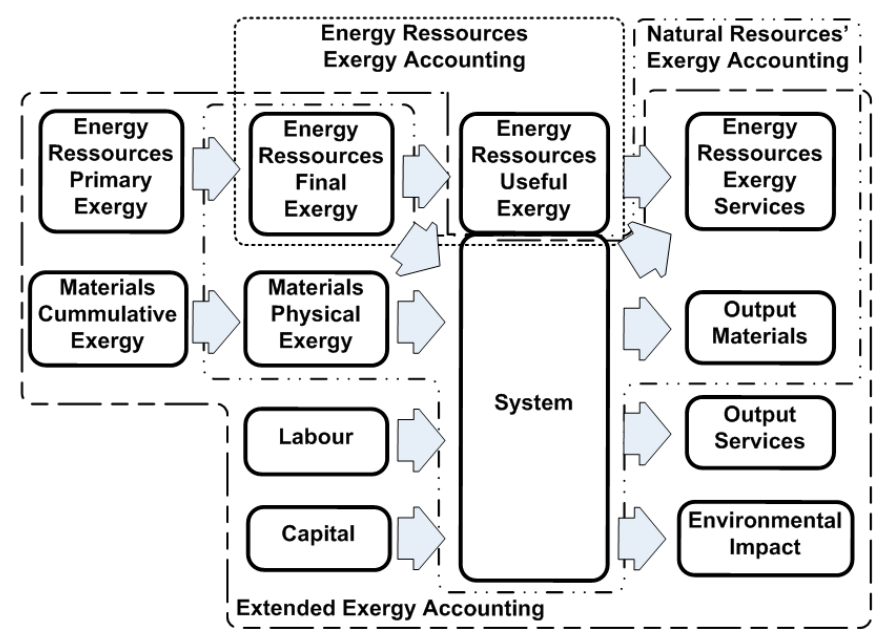

Figure 1. Exergy accounting methodologies. 
EREA quantifies the useful exergy that is available for each end use, but does not inform on how well that exergy service is being used. To illustrate, consider two similar gasoline vehicles on a highway, the first with only one passenger and the second with five people on board. When assessing both systems by EREA the useful exergy is the same since the energy carrier-end use pairs are the same (gasoline-transportation). However, when measuring the system output, in this case the number of passengers times distance, the performances are widely different.

NREA is an input-output assessment where all energy and matter that enters and leaves the system is accounted for (Figure 1). Contrary to EREA, no information on how each energy carrier is used is needed but more data is required to account for all fluxes across system boundaries. By accounting both the input and output fluxes, the NREA approach measures the overall physical performance of the transformation process.

Finally, EEA is similar to NREA but also introduces capital and labour as inputs and environmental impact as a virtual input, integrating the social, economic and environmental pillars of sustainability. Translating capital, labour and environmental impact externalities into an exergetic cost is a key feature of EEA as it reflects the real thermodynamic system's efficiency and the usually hidden resource costs [8]. The production factors are no longer just energy resources (EREA) or energy and matter (NREA) but also immaterial flows which are essential to assess the system's behaviour (Figure 1). The exergy of inputs is no longer the physical and chemical exergies but the cumulative exergy introduced by [9] in the cumulative exergy consumption methodology (CExC). The latter takes into account the sum of all the exergetic content of resources that are consumed in a production chain. Consequently, the main focus of EEA is to find the real exergy embodied into the output flows under study, adding not only all exergy necessary to bring all inputs to the specific space and time domains but also all labour, capital and environmental impacts.

First exergetic studies focusing exclusively on agriculture adopted an EREA approach and included conversion in agriculture machinery, such as tractors, and electric pumps. Agricultural sectors of Saudi Arabia [10], Turkey [11], Jordan [12], Iran [13] and finally Malaysia [14] were studied longitudinally (except for Jordan) in order to verify the evolution of efficiency. The efficiencies of devices vary widely among studies.

First exclusive NREA approaches to agriculture also included virtual environmental impact as an input to integrate pollutant emissions [15]. The input-output ratio was approximately 10 (ten times more exergy in inputs than outputs) but solar radiation was responsible for 90 to $95 \%$ of the inputs with an estimated photosynthetic efficiency of $4.5 \%$. A combination of EEA and cumulative exergy extraction from the natural environment was proposed by [16] to measure the agricultural performance of 29 countries from 1990 to 2003. As important findings, the study highlighted the three types of resources that agricultural production most extracts from the natural environment: organic content in top soil, feed and water. Finally, it concluded that the exergy efficiency in the livestock sector is much lower than in the crop sector.

Some societal exergy studies that use the EREA approach, also included, in detail, the AFF sector $[17,18]$. These studies have allocated all energy carriers (e.g., diesel) used in the AFF sector to end-uses (e.g., mechanical drive). The AFF sectors of Sweden [19,20], Japan [21] and Italy [22] were assessed by the NREA methodology where the major energetic and material inputs were considered along with all the production from the sector. EEA studies also addressed the AFF sector. Efficiencies estimated by the EEA approach for the province of Siena, Italy [23]; the U.K. economy [24]; Chinese society [25-29], and the economy of Nova Scotia, Canada [30] were all below 100\%. These EEA studies did not take into account solar radiation, but considered crops and wood as extractions from the environment and not as productions.

All three methodologies have been used to assess the performance of society [31] and of the AFF sector. However, analyses typically focus on results provided by only one methodology without justifying the use of that specific methodology in detriment of others. Also, there are major differences in the exergy inputs and outputs that are accounted for, across published NREA and EEA analyses of 
the agricultural sector. This is problematic if results provided by the three methodologies or even by the same methodology are inconsistent driving to different policy recommendations.

The present study evaluates the performance of the agricultural sector in Portugal, between 2000 and 2012, applying three exergy methodologies: the energy carrier's exergy accounting approach, the natural resource's exergy accounting approach and the extended exergy accounting.

\section{Methodology and Data}

\subsection{Exergy Accounting of Energy Resources}

Appendix A briefly revisits the exergy concept. More detail can be found in [32]. EREA measures the useful exergy services delivered to each end use. EREA estimates the system's useful exergy by multiplying the intrinsic exergy applied to the system by the specific real efficiency for each energy carrier in its dominant end use. The efficiencies reflect the actual performance of the machinery or device that uses the energetic carrier in each end use (Figure 2). The accounting methodology is done in four separate steps $[17,32]$. First, all final energy that enters the system is converted into final exergy, multiplying each carrier by its exergy factor. Second, end-uses are allocated to each energy carrier. Third, a real exergy (or second law) efficiency is attributed to each carrier-end use pair based on the actual final to useful transformation devices involved. Finally, all useful exergy obtained from each end use category are added to discover the overall system's useful exergy delivery and calculate an output-input ratio to assess the efficiency of the transformation process.

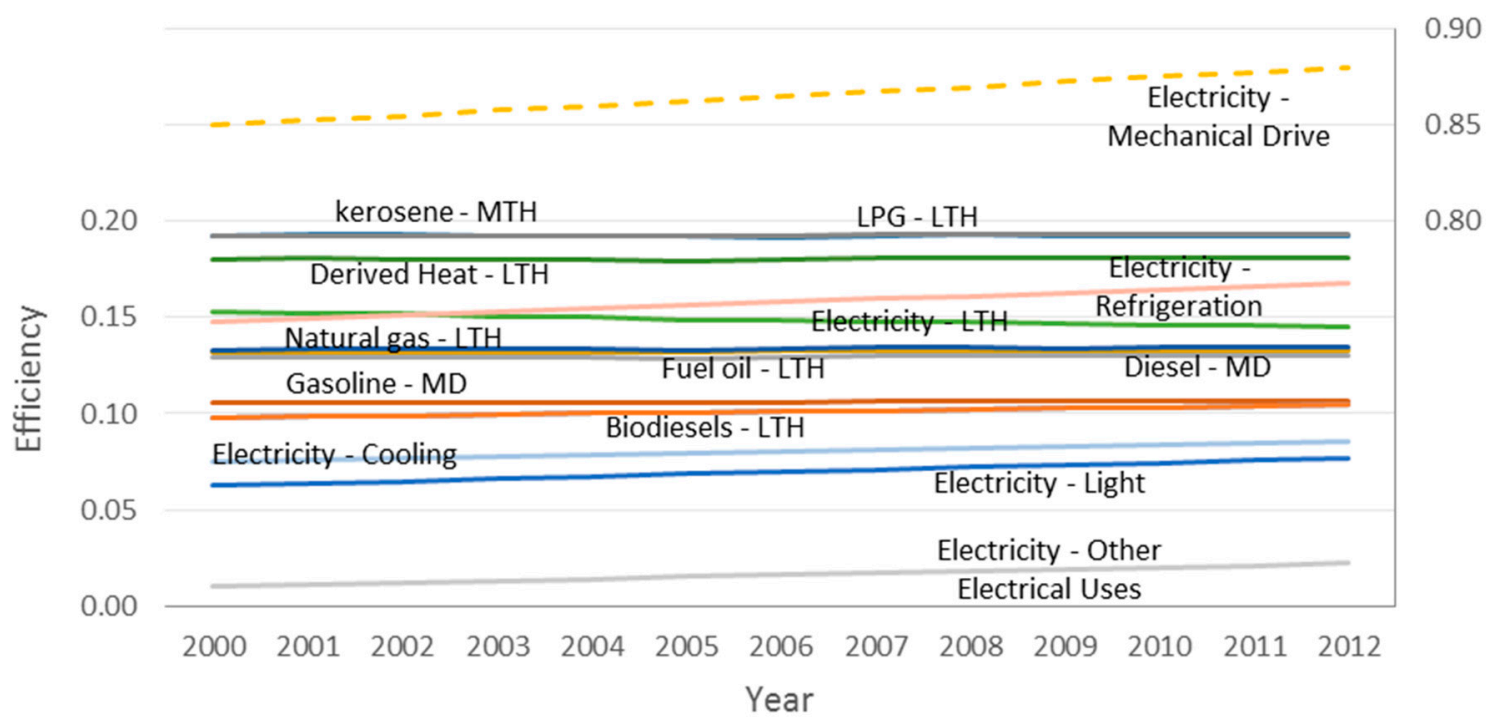

Figure 2. Energy carriers' conversion efficiency from 2000 to 2012 (full lines on the left axis and dashed line on the right axis).

\subsubsection{End Use Categories}

From all energy carriers presented in the statistical data, natural gas, biofuels, heat production and fuel oil were predominantly used in low temperature heat processes while liquefied petroleum gas and kerosene were mainly used to support medium temperature heat devices. Gasoline and diesel were prevalent in motors in fisheries and agricultural machinery, being used mainly for transportation in the fisheries subsector and mechanical drive in general (including transportation) in crops, husbandry and forestry [17]. Electrical energy was used for several end uses: $26.7 \%$ for low temperature heat (water and process heating), 51.7\% for mechanical drive (irrigation, material handling and other process use), $5.0 \%$ for lighting, $4.2 \%$ for cooling (AC), $10.0 \%$ for refrigeration (industrial cooling) and $2.4 \%$ for other electrical equipment like phones, computers and network devices [33]. 


\subsubsection{Conversion Efficiencies}

Efficiencies vary by end use and by energy carrier since the technologies involved are different. Low temperature heat (LTH) efficiencies considered were 10\% for solid biofuels and biodiesel, $13 \%$ for natural gas and fuel oil, $15 \%$ from electricity and 18\% from derived heat. Medium temperature heat (MTH) achieved better efficiencies since higher temperature flows have higher exergetic content. Both liquefied petroleum gas and kerosene were considered to have a 19\% transformation efficiency. Gasoline and diesel were used for transportation and mechanical drive (MD) with $11 \%$ and $13 \%$ efficiencies, respectively. Also electricity was used to drive mechanical appliances with an increasing efficiency from $85 \%$ in 2000 to $88 \%$ in 2012 (Figure 2). All efficiency values were obtained from $[34,35]$.

\subsection{Natural Resources' Exergy Accounting Approach}

The NREA approach consists in quantifying all energy and matter that enters and leaves the system in the common unit of exergy. Contrary to EREA where the system is analysed in order to understand how the energy resources are used, in this methodology the system is evaluated only by quantifying the inputs and outputs, without any knowledge about the system's internal behaviour (Figure 3). The ratio between outputs and inputs will reflect how well energy and matter are being used and offers insights on the sustainability of the agricultural sector. Although the amount of data is usually a lot bigger than in EREA, the methodology is simpler to apply since we only have to address the exergetic content for each flux across the system's boundaries.

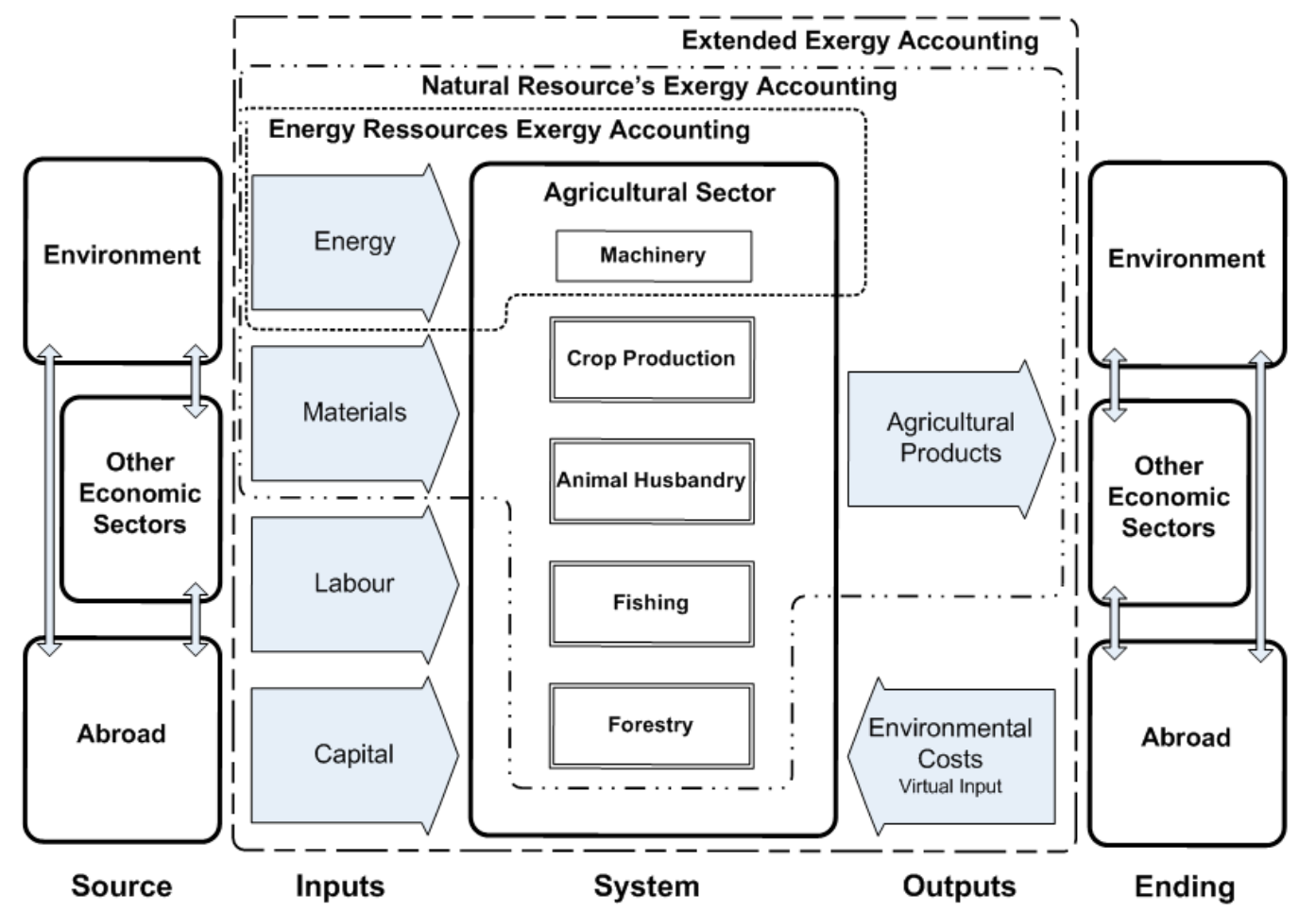

Figure 3. Exergy accounting methodologies for the Agricultural, Forestry and Fisheries Sector.

In this study, there is a clear distinction between the Agricultural, Forestry and Fisheries Sector and the environment (see Figure 3) focusing on the efficiency of anthropogenic activities. We consider crops, wood removals and fish from aquaculture as outputs because they are a product of an anthropogenic activity. In contrast with other studies [23-30] we do not count them as an extraction from the environment because they do not appear spontaneously. In contrast, we consider fish catch as a natural input from the environment. 


\subsection{Extended Exergy Accounting Approach}

Extended exergy analysis adds, on top of natural NREA, the immaterial inputs that are crucial to run and maintain the system working and also adds the environmental impact as a virtual input (Figure 3). Labour and capital exergy estimations are based on two postulates elaborated by Sciubba [36], defending that the global influx of exergy resources are mainly used to sustain workers and, that the capital exergy flux is proportional to the labour exergy flux. The proposed equation to evaluate the exergy used to sustain all workers is (exergy of labour): $E_{L}=f \times e_{\text {surv }} \times N_{h}$, where $f$ is an amplification factor that represents the society consumption over the survival mode, $e_{\text {surv }}$ is the minimum exergy required to maintain healthy metabolic needs $(2500 \mathrm{kcal} /$ day per person or $1.05 \times 10^{7} \mathrm{~J} /$ day.person) and $N_{h}$ is the total population. The amplification factor is estimated using the Human Development Index (HDI) [37] which, based on three social dimensions, reflects the development of a country, $f=\frac{H D I}{H D I_{0}}$, being $H D I_{0}$ the Human Development Index of a pre-industrial society $\left(H D I_{0} \approx 0.055\right)[36]$. Labour equation implies that $E_{L}$ is linearly dependent on the HDI and independent of the fraction of workers in the society and the type of work. The exergy equivalent of Labour $\left(e e_{L}\right)$ for the society, or economic sector, can be calculated dividing the exergy of labour by the total hours worked $\left(N_{w h}\right), e e_{L}=\frac{E_{L}}{N_{w h}}$.

Seckin et al. [38] followed by Rocco et al. [8] slightly changed the equation proposed by Sciubba [36] for the exergy of the capital flux from $E_{K}=\frac{M_{2}}{S} \times E_{L}$ to $E_{K}=\frac{M_{2}-S}{S} \times E_{L}$ where $S$ is sum of all wages and $\mathrm{M}_{2}$, defined by the European Central Bank [39], is an intermediate monetary aggregate which reflects the currency under circulation plus the liquid deposits (maturity up to 2 years and redeemable up to 3 months). The new formulation considers $\mathrm{M}_{2}-\mathrm{S}$ because labour (reflected as the wages in the previous formula) was already internalized as an exergetic flux. The exergy equivalent of capital is obtained by dividing the total exergy of the capital flux by the monetary circulation, $e e_{K}=\frac{E_{K}}{M_{2}-S}$. Capital equation assumes that the monetary aggregate $\mathrm{M}_{2}$ minus wages is eligible to the productive sector and represents the effective capital that drives all economic sectors. To translate money into exergy, the capital equation assumes the relationship developed for labour: $e e_{K}=\frac{E_{K}}{M_{2}-S}=\frac{E_{L}}{S}$.

Any material stream that is not physically confined and represents a discharge of the system to the environment is considered a pollutant. The environmental impact in EEA consists in developing a state-of-the-art process to bring the pollutant wastes and emissions to equilibrium with the reference environment. The total amount of exergy used in the innovative process is accounted for as an environmental externality and a virtual input to the economic sector. The equivalent exergy of the environmental impact portrays all exergetic consumption to run such a process (real or virtual) namely energy, matter, capital and labour having no relation with the pollutant physical exergy.

\subsection{Reference Environment}

The reference environment should be carefully chosen since the resource flow has exergy due to the imbalance (lack of equilibrium) with this reference state. The flow will have zero exergy in complete equilibrium with the reference state. In this study, the pressure $\mathrm{P}_{0}=101325 \mathrm{~Pa}$ and temperature $\mathrm{T}_{0}=298.15 \mathrm{~K}$ were adopted as well as the standard chemical composition of the natural environment. This is the reference environment used by Kotas [40] to estimate chemical exergy values that were used in this study.

\subsection{Time Window and Control Volume}

Recent exergy studies of countries or large regions focus on the seven economic sectors of society plus the environment and abroad $[24,30,41]$ (see Table 1). 
Table 1. Description of Economic Sectors, Environment and Abroad.

\begin{tabular}{cl}
\hline Extraction (Ex) & Extraction of minerals and ores, coal mining, oil and gas extraction, refining and fuel manufacturing. \\
\hline $\begin{array}{c}\text { Conversion (Co) } \\
\text { Agriculture, Forestry and } \\
\text { Fisheries (AFF) }\end{array}$ & $\begin{array}{l}\text { Power, cogeneration and heat plants, based on renewables and non-renewables. } \\
\text { products like milk, honey and eggs. }\end{array}$ \\
\hline Industry (In) & All manufacturing industry excluding refining. \\
\hline Tertiary (Te) & $\begin{array}{l}\text { Public and private sector services, includes schools, hospitals, construction, trade and commerce, } \\
\text { tourism, real estate and finance. }\end{array}$ \\
\hline Transportation (Tr) & Private and commercial transportation of people and goods. \\
\hline Domestic (Do) & Includes households and population. \\
\hline Environment (E) & Lithosphere, the hydrosphere and the atmosphere. \\
\hline Abroad (A) & $\begin{array}{l}\text { Other countries or regions outside de economic system boundaries which allow energy and } \\
\text { mass transfers. }\end{array}$ \\
\hline
\end{tabular}

This study focuses on just one economic sector, the AFF, because of the relevance and preponderance in sustaining human life. Figure 4 exhibits the agricultural sector within the region's economy and specifies inputs and outputs considered for this study.

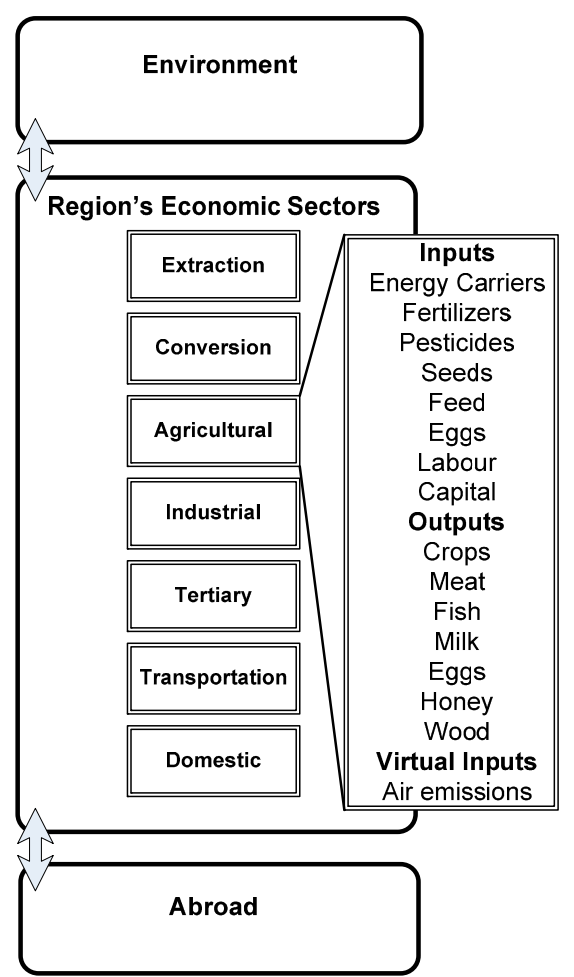

Figure 4. Inputs and outputs of the Agriculture, Forestry and Fishery (AFF) sector.

Time and regional boundaries were chosen in accordance with the available data, since few data were available posterior to 2012 and there was a lot of missing data prior to 2000 .

\subsection{Data}

The statistical office of the European Union, Eurostat, provides in its database [42] the quantities of energy carriers, pesticides, fertilizers, harvested crops, meat slaughtered, fish catch, incubation eggs, milk collection, fish aquaculture, wood removals, atmospheric emissions, population, human labour and economic information. The energy of energy carriers was assumed to be the lower heating value (LHV) and the exergy factors for the energy carriers are the ratio of the standard chemical exergy of the organic fuels to the LHV, these factors being obtained from $[40,43,44]$. However, the 
consumption matrix of energy carriers is only available in two branches, being the first the agricultural plus the forestry subsectors and the second is the fisheries subsector. Also the data for pesticides and fertilizers is not disaggregated between agriculture and forestry subsectors. Due to this limitation and not wanting to apply some educated division between these carriers on both subsectors, all aggregated results will be presented in the conjunction of the agriculture and forestry subsectors.

Crop seeds, feed, produced eggs and honey carriers and some nutritional energy values for products not intended for human consumption were obtained from the statistics division of the Food and Agriculture Organization of the United Nations (FAOSTAT) [45]. Nutritional energy values assigned to each food element, in its raw state, are from USDA (United States Department of Agriculture) National Nutrient Database [46]. Moisture content of all food items was considered to be equal between USDA and Eurostat databases. All economic values such as compensation for employees, agricultural gross value added (GVA), monetary aggregate M2 and gross domestic product (GDP) were obtained at current prices and converted to constant euro GDP prices through a GDP price deflator obtained from the economic and financial affairs of the European commission (Ameco) [47]. The GDP price deflator is referenced to 2010 and measures the ratio between real GDP and the nominal GDP, providing a measure of inflation over the period.

Agricultural outputs were obtained in mass units, except wood which was available in volume units, and converted to exergy units using the energetic nutritional value presented in the USDA database [46] or in FAO (Food and Agriculture Organization of the United Nations) nutritive factors table [48], for food compounds.

The food (and feed) energy content was considered equal to the metabolizable energy as defined by [46]. The energy content (combustible or gross energy) of the ingested food should be measured by a bomb calorimetry. However, foods are not fully digested and absorbed by the organism. From the ingested or gross energy, some is lost to faeces (faecal energy) and gases (combustible gas), the rest is the digestible energy. Subtracting from the digestible energy, the energy that is lost is urine and heat results in metabolizable energy [49]. Data available from the United States Department of Agriculture for food energy is based on the Atwater system which is equivalent to the metabolizable energy [46]. The choice to use the metabolizable energy was mainly due to the lack of a complete database of combustible or gross energy.

The aggregate of food energy values presented are not fully ingested by society. Food supply chains cover five steps: agricultural production, postharvest, handling and storage, processing and packaging and finally distribution and consumption. In each step food is lost or wasted and the total in Europe reaches $31 \%$. For Europe, at the producer level, food losses and waste accounts $2 \%$ for cereals, $3.1 \%$ for meat, $3.5 \%$ for milk, $9.4 \%$ for fish and seafood, $10 \%$ for oilseeds and pulses and $20 \%$ for roots, fruits and vegetables [50]. Such losses are not edible for societal consumption.

To fill in the gaps for a given resource or product, in a year or more, data was interpolated (between known values) or extrapolated (in extremes of the data set) by a linear regression made from all the other known values.

Fluxes inside the sector were not considered and only fluxes between sectors that have economic relevance were accounted for. Although seeds, feed and incubations are produced by the sector, they were considered to leave the agricultural sector to other economic activities (ex. industry or tertiary) and returned as an input, essential to the production. However straw, green fodder and manure (used as a fertilizer) that are internal inputs and outputs of activities within the sector were not accounted for.

Solar radiation, vital for crop production, and water, essential for crops and livestock, were not included in the study. The sun radiation is not an anthropogenic controlled flux and it can be seen as a flux from the environment with no economic value. Water from rain follows the same thinking as it is not an anthropogenic activity but irrigation water should have been an input although the lack of trustworthy data prevented its use in the study.

Animal skins production data (including wool) is only available for goats and sheep but the absence of a specific exergetic value for skins lead us to consider only the wool production flux that 
has a specific exergy of $5850 \mathrm{~kJ} / \mathrm{kg}$ [51]. However, its exergetic value is very low ranging from $51 \mathrm{TJ}$ in 2000 to $35 \mathrm{TJ}$ in 2012. Other animal products such as lanolin or cow's leather were not accounted for, due to lack of data. For lanolin and cow's leather there are no specific exergetic values while for cow's leather there is also no production data.

Wood removals are considered as under bark and the exergy values were obtained from Dewulf et al. [52]. Dry matter exergy values are $22.11 \mathrm{MJ} / \mathrm{kg}$ for softwoods and $22.01 \mathrm{MJ} / \mathrm{kg}$ for hardwoods and densities of $450 \mathrm{~kg} / \mathrm{m}^{3}$ and $650 \mathrm{~kg} / \mathrm{m}^{3}$ respectively. Moisture content was assumed to be $20 \%$.

Environmental remediation exergy costs were estimated by multiplying the pollutant air emission (obtained in mass units) by the specific extended cost of removing the pollutant from the atmosphere. Studying the transportation sector for Turkey, Seckin et al. [38] also created a virtual process to find the environmental extended exergy cost of three pollutants: carbon dioxide $(57,600 \mathrm{~kJ} / \mathrm{kg})$, methane $(322,400 \mathrm{~kJ} / \mathrm{kg})$ and nitrous oxide $(10,600 \mathrm{~kJ} / \mathrm{kg})$. Dai et al. [53] studying the transportation sector in China determined the specific environmental remediation exergy cost of carbon monoxide $(11,800 \mathrm{~kJ} / \mathrm{kg})$, nitrogen oxides $(3610 \mathrm{~kJ} / \mathrm{kg})$ and sulphur oxides $(5890 \mathrm{~kJ} / \mathrm{kg})$. For ammonia, the chemical exergy was used as the extended exergy cost of removing the pollutant (since no study is available in the literature) and valued by $19,841 \mathrm{~kJ} / \mathrm{kg}$.

\section{Results}

\subsection{Energy Resources' Exergy Accounting}

\subsubsection{Energy Resources}

Energy resources are essential as they fuel all the machinery applied in the AFF sector. In the agriculture and forestry subsectors, energy use decreased drastically, more than $50 \%$, mainly due to the decrease in the use of diesel to one third of the initial value (Figure 5).

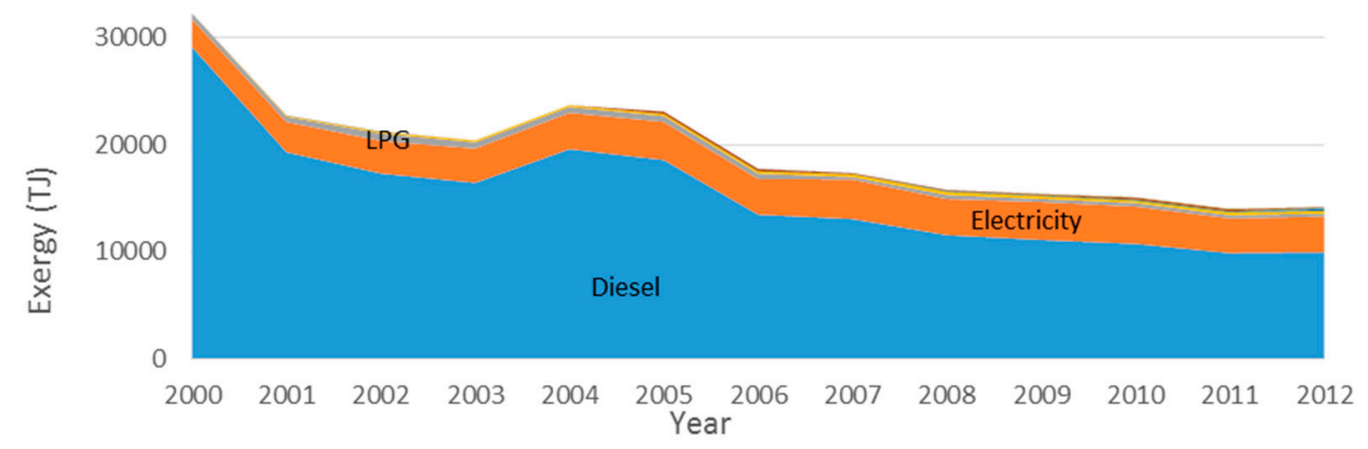

Figure 5. Exergy of energy resources' inputs to agriculture and forestry.

In contrast to agriculture and forestry, the consumption of energy resources in fishery has almost tripled due to the diesel carrier (Figure 6). In this subsector, LPG (Liquefied Petroleum Gas) and gasoline were also replaced by biodiesels and electricity. Notably, electricity grew from an $8 \%$ share in 2000 for agriculture and forestry to $23 \%$ in 2012 while in fishery and aquaculture (just fishery subsector from now on) it increased from $2.6 \%$ to $7.1 \%$ in 2012 . 


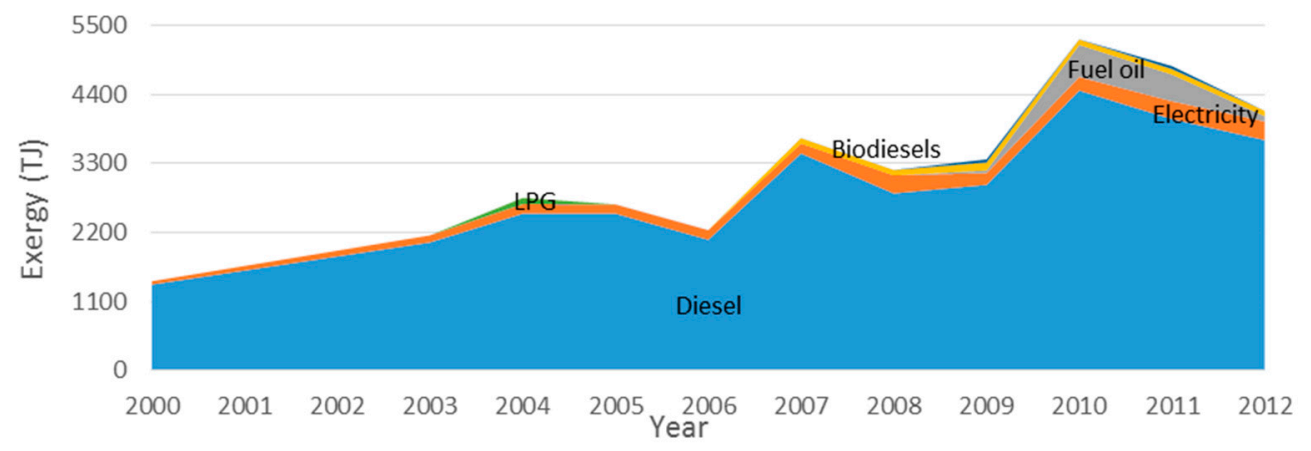

Figure 6. Exergy of energy resources' inputs to the fishery subsector.

\subsubsection{End-Uses}

Mechanical drive (e.g., tractors, irrigation pumps) and transportation (ex. boat engines) consume the biggest share of useful exergy in the sector. The decrease of $56 \%$ in the exergetic input of energy carriers in agriculture and forestry, from 2000 to 2012, was reflected in a 39\% decrease in the amount of useful exergy applied to both subsectors (Figure 7). Fisheries increase energy carriers' consumption by $291 \%$ and obtained a $320 \%$ increase of useful exergy (Figure 8). Both improvements are associated to an increasing final-to-useful efficiency and are mostly due to the increased use of electricity, namely in irrigation.

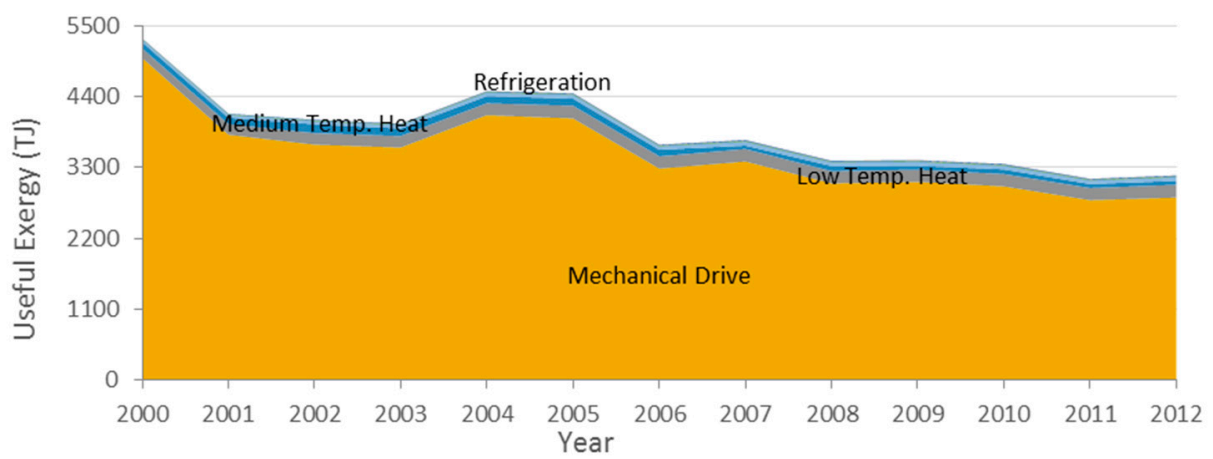

Figure 7. Useful Exergy by end use category in agriculture and forestry.

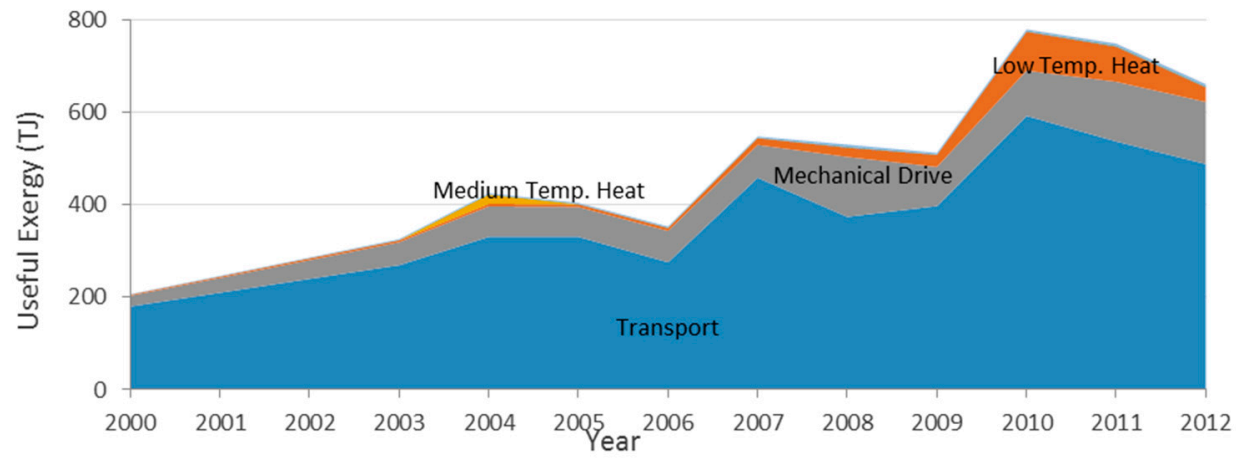

Figure 8. Useful Exergy by end use category in fisheries.

\subsubsection{Sector and Subsector Efficiencies}

All subsectors have increased their efficiency (Figure 9) with agriculture and forestry showing a better performance. The increase in the share of electricity and the reduction of the share of diesel (mostly associated to the transition from diesel-powered to electrically-powered irrigation pumps) 
allowed an increase in performance of 38\% (from 16\% to 22\%) for agriculture and forestry and 30\% (from $16 \%$ to $21 \%$ ) overall. Fishery also increased their conversion efficiency from energy carriers to useful exergy from more than $14 \%$ to $16 \%$.

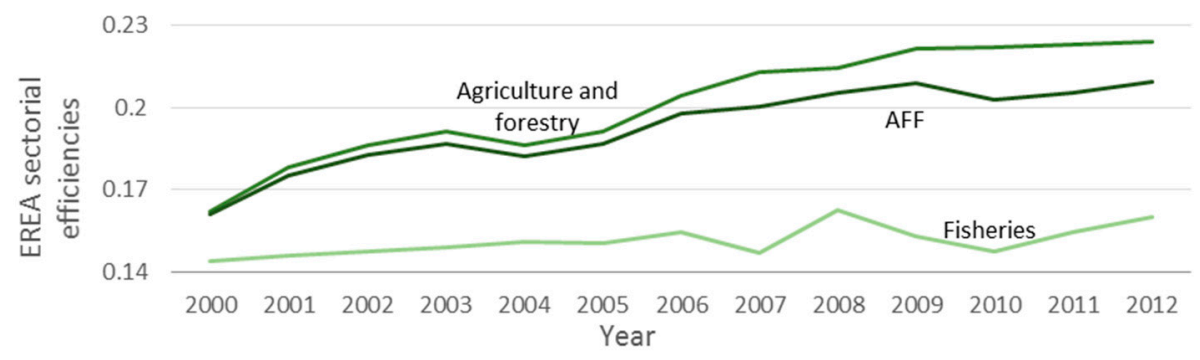

Figure 9. AFF sector and subsectors efficiencies by EREA approach.

To test whether the increase in efficiency was only due to technological improvements we estimated EREA subsectorial efficiencies assuming the carrier end-use pairs efficiencies were constant from the year 2000 onwards (Figure 10). In these conditions, the useful exergy per final exergy would have increased $35 \%$ for agriculture and forestry (from 16\% to $22 \%$ ), $8 \%$ for fishery (from $15 \%$ to $16 \%$ ) and $27 \%$ overall (from $16 \%$ to $21 \%$ ), showing that the overall increase in efficiency was due not only to better technologies but also reflect a wiser choice of energy carriers for the desired end-use.

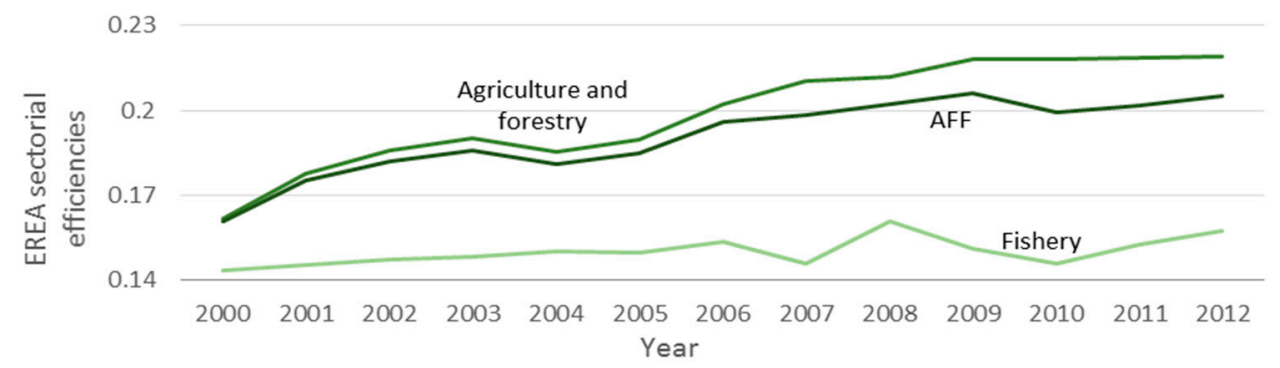

Figure 10. AFF sector and subsectors efficiencies by EREA approach considering year 2000 carrier-end use efficiencies.

\subsection{Natural Resources' Exergy Accounting}

\subsubsection{Total Outputs}

About two thirds of all agricultural, forestry and fisheries exergetic output is from wood removals. The changes in the overall annual production that ranges between $140 \mathrm{PJ}$ to $160 \mathrm{PJ}$ are controlled by changes in wood production (for a more detailed description see Appendix B). The aggregated production intended for food and feed decreased $14 \%$ mainly due to a $20 \%$ decrease in crops harvested despite a $20 \%$ increase in meat production (Figure 11).

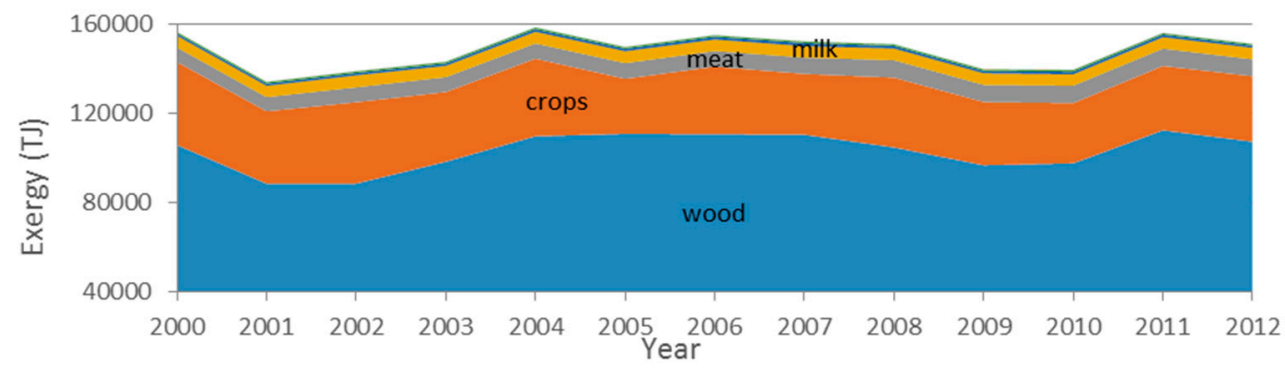

Figure 11. Natural resources exergy output from the AFF sector. 
The production matrix for the Portuguese AFF sector has remained almost constant, being forestry the major producer and increasing its share. Fishery nutritional values are neglected while energetic values for animal husbandry are constant and the share of vegetables and fruits have decreased, mainly after 2004 (Figure 12).

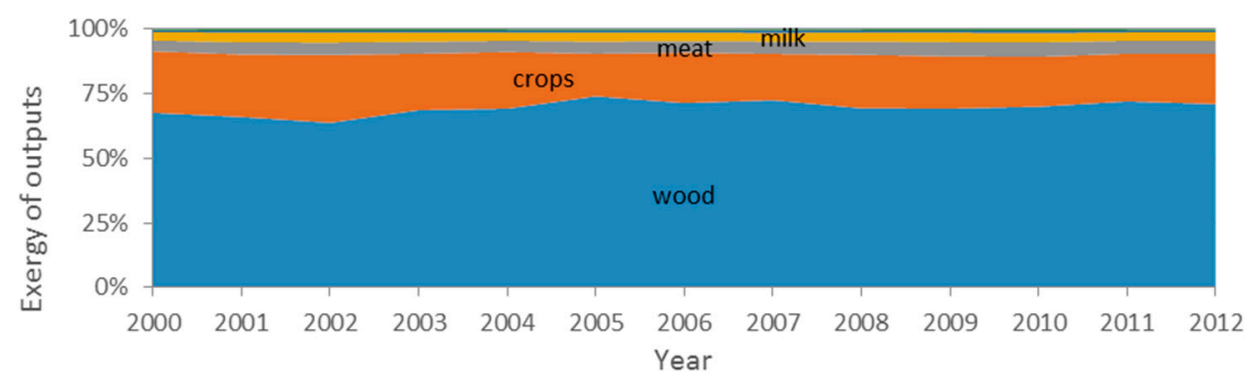

Figure 12. Natural resources exergy output from the AFF sector in percentage.

\subsubsection{Total Inputs}

Overall input to the agricultural sector is decreasing ( $24 \%$ over the 13 years) mainly due to fewer amounts of energy resources which alone represented 29\% of all inputs in 2012 (Figures 13 and 14). Seeds, fertilizers, pesticides and eggs for incubations were almost negligible in the sector's consumption matrix while feed is by far the biggest input (for a more detailed description see Appendix C).

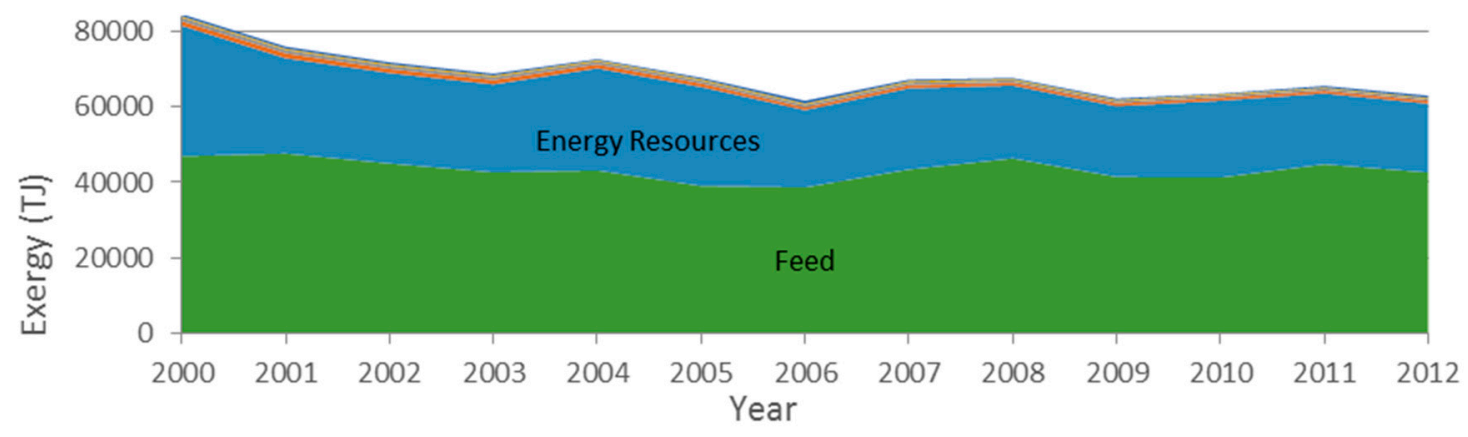

Figure 13. Natural resources exergy inputs to the AFF sector.

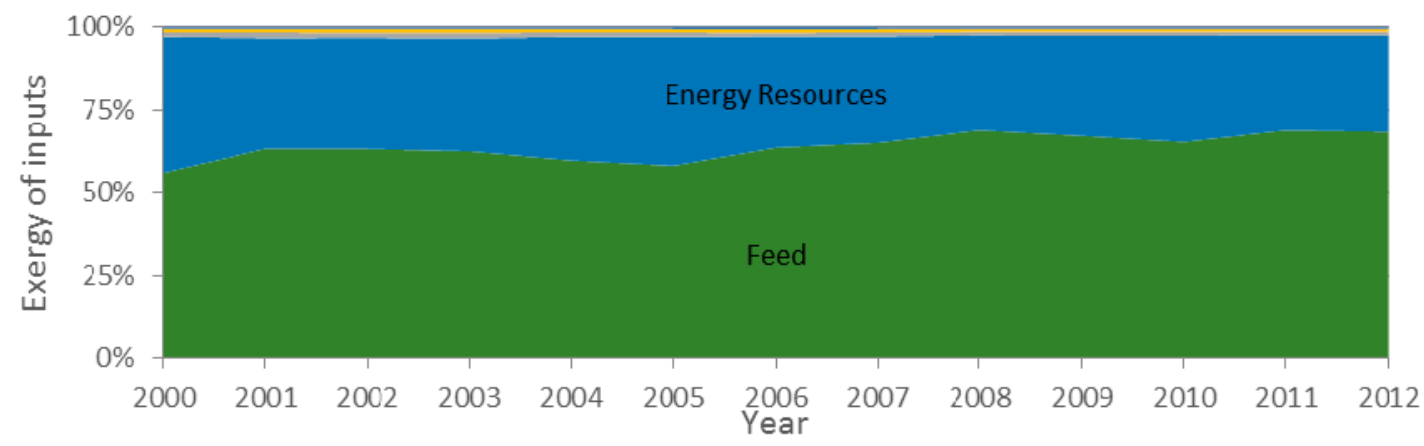

Figure 14. Natural resources exergy inputs to the AFF sector in percentage.

\subsubsection{Sector and Subsector Efficiencies}

The agricultural sector relies heavily on environmental conditions to sustain production. Water and radiation are offered freely by our natural environment and do not constitute a societal activity. Their contribution leads to efficiencies higher than $100 \%$ for agriculture and forestry. 
This subsector reached a 255\% efficiency in 2012, a 36\% increase since 2000, contrasting with fishery, which decreased its efficiency by 53\% from a 43\% efficiency in 2000 to 20\% in 2012 (Figure 15).

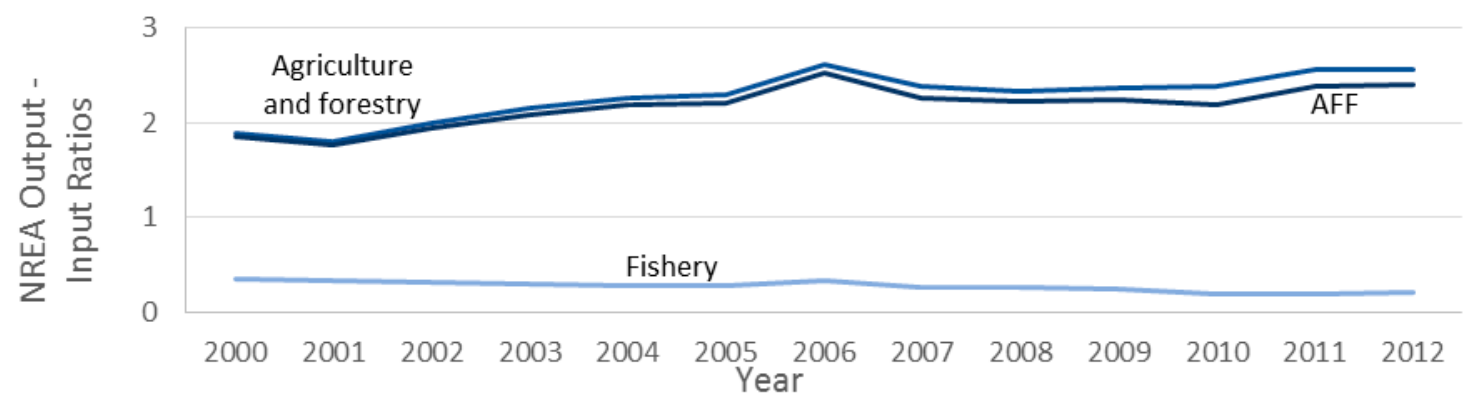

Figure 15. AFF sector and subsectors efficiencies by NREA approach.

\subsection{Extended Exergy Accounting}

The inclusion of three new production factors offers a new perspective of the AFF sector and allows comparisons between material and immaterial inputs. Exclusively for the three immaterial inputs of the EEA approach, the agriculture and forestry subsectors are quantified separately to allow comparisons between them.

\subsubsection{Labour}

Total exergy allocated to labour was calculated by the labour equation with HDI values from the United Nations Development Programme-Human Development Reports [37] and total population and number of workers data from the Eurostat database [42]. These values as well as other labour and capital statistics are available in Appendix D. To measure the associated labour exergy to the AFF sector and subsectors, the total societal labour exergy was multiplied by the fraction of workers in this sector and subsectors. This assumes that all workers have the same labour exergy independently of the sector or even the working hours, which is consistent with the equation used.

The number of workers and respective labour exergy is far superior for agriculture over forestry and fishery (Figure 16). Total labour exergy remained constant due to an increase in the HDI values and to a decrease in the number of workers in the AFF sector. Overall equivalent exergy of labour increased rapidly from $51.5 \mathrm{MJ} / \mathrm{h}$ in 2000 to $89.0 \mathrm{MJ} / \mathrm{h}$ in 2012 which means that the necessary societal exergy to produce one hour work increased $73 \%$ in 13 years. Although the cost of labour was similar, in the beginning of the century, for all three subsectors, in 2012 the necessary exergy to supply one hour work to agriculture was 30\% higher than to forestry and fishery. This increase was due to the decrease in the number of hours worked per year by farmers from about 2000 to less than $1500 \mathrm{~h}$ in 2012.

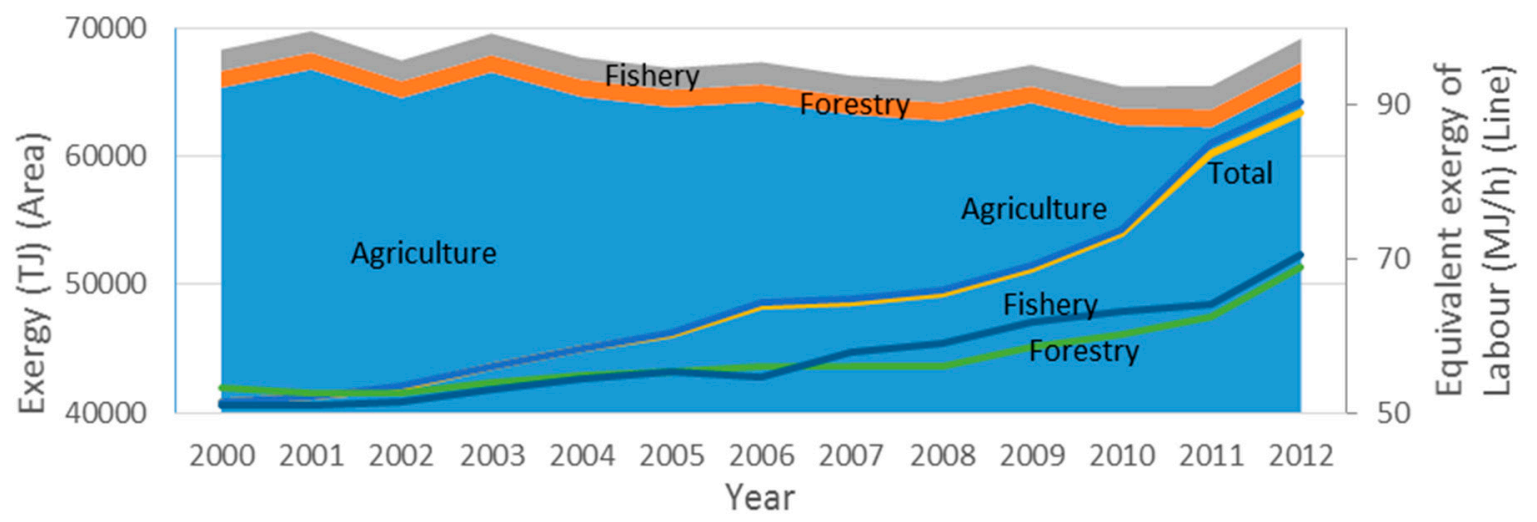

Figure 16. Exergy of labour into AFF subsectors and equivalent exergy of labour. 


\subsubsection{Capital}

In addition to labour, capital is a fundamental key for a productive system and should also be introduced as an input. To discover the monetary aggregate associated to the AFF sector, a direct relation was made between M2 and total gross value added (GVA) of the country (which in case of Portugal is almost identical). The monetary aggregate of the sector and subsectors under analysis was obtained assuming a linear relationship with the GVA of the AFF sector and subsectors allowing the calculation of different equivalent exergy of capital $\left(\mathrm{ee}_{\mathrm{k}}\right)$ for each of the three subsectors. Capital exergy relates to labour exergy through the ratio $\frac{\mathrm{M}_{2 S}-\mathrm{S}_{\mathrm{S}}}{\mathrm{S}_{\mathrm{S}}}$ which is higher than 1 , reaching 8 for forestry. The $\mathrm{S}$ subscript in the previous equation means that the considered values are sector or subsector related.

The exergy of capital has decreased $42 \%$ from 2000 to 2012, mainly due to a strong decrease in AFF's GVA (Figure 17). The equivalent exergy of capital has been constant for all subsectors with the agriculture subsector presenting the highest value. The explanation is that the wage per hour in agriculture subsector is more than five times lower than in fishery or forestry, although there was a $73 \%$ increase in the wage per hour in agriculture (in 13 years) compared to an $18 \%$ increase for forestry and $12 \%$ for fishery (at constant 2010 prices).

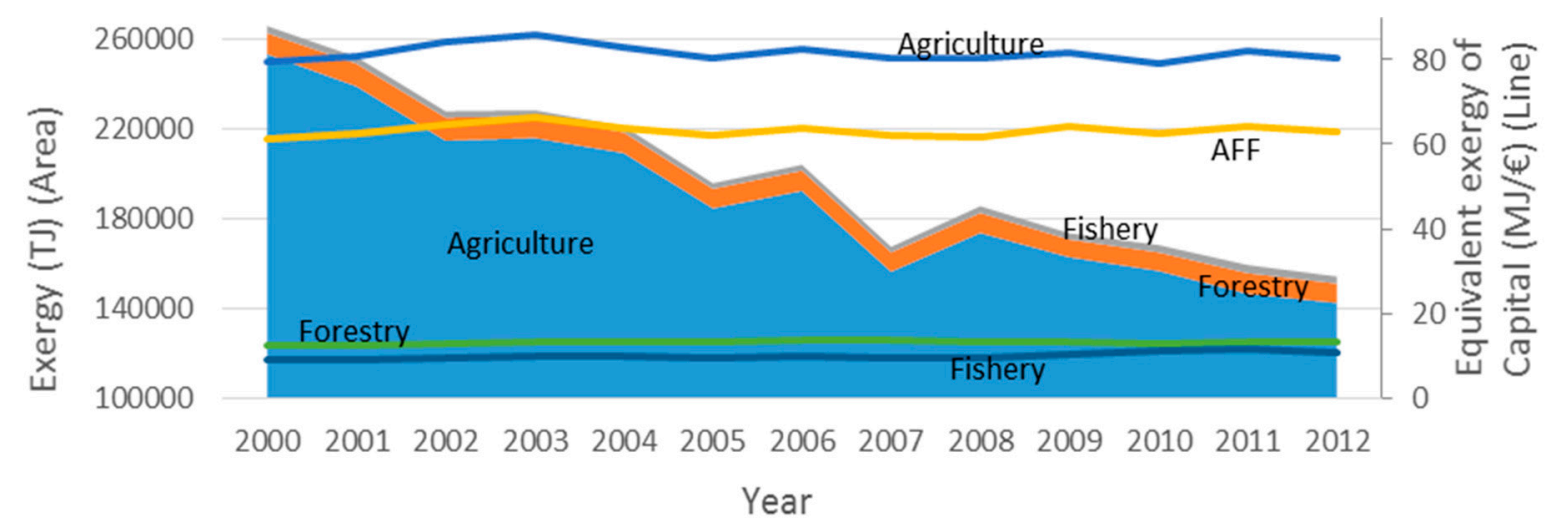

Figure 17. Capital exergy into AFF subsectors and equivalent exergy of capital.

\subsubsection{Environmental Impact}

The EEA considers that the exergy value of the waste or pollutant should not be his chemical exergy but the extended exergy cost to avoid the pollutant or bring the pollutant to the dead state. Such extended exergy costs are the sum of all physical exergy required to run the cleaning process plus the labour and capital exergy fluxes imperative to run the process [54]. Carbon dioxide is mainly emitted from the combustion of fossil and renewable fuels; emissions from biomass (not used as fuel) were not accounted for because in a life cycle perspective biomass is neutral. Emissions by animals comprise carbon dioxide and methane from enteric fermentation in the ruminants' digestive system. The methodology doesn't account carbon dioxide from animal husbandry but accounts methane emissions, being the total amount almost exclusively from livestock production (Figure 18). The total exergy needed for environmental clean-up from atmospheric emissions is the biggest input of the system showing a decrease of $10 \%$ over the years. Carbon dioxide represents almost two thirds of the equivalent exergy and methane the remaining part, being the exergy from the other pollutants residual. Methane emissions follow the trend line of animal husbandry production (almost constant) and carbon dioxide follows the decreasing trend line of energy resources. 


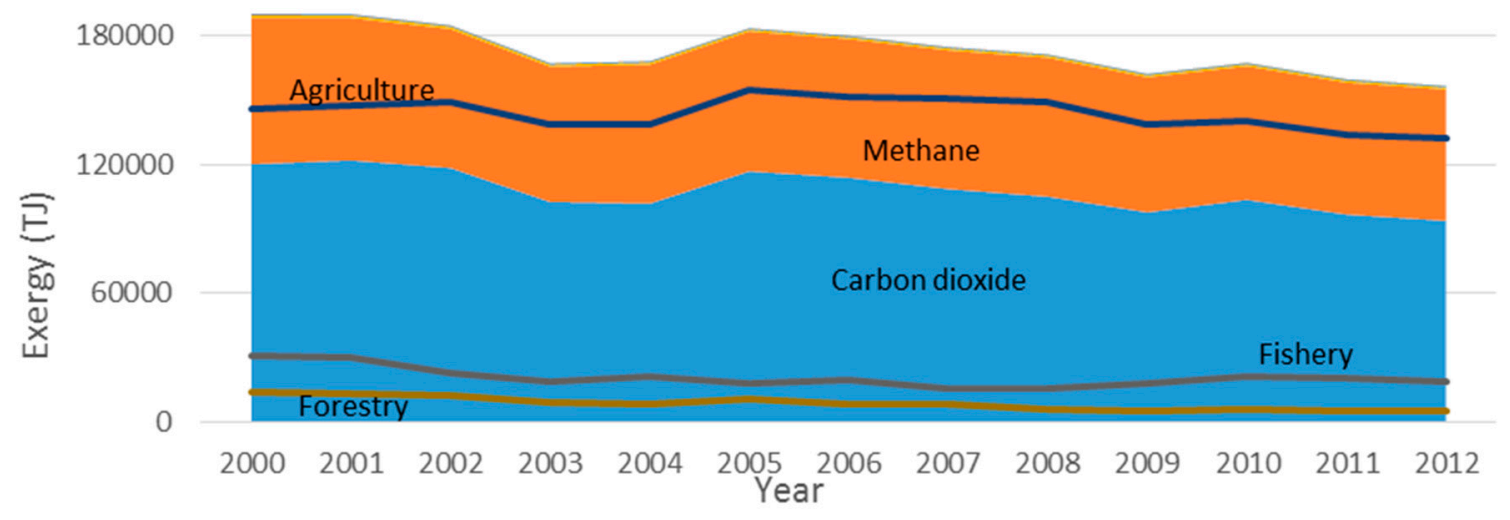

Figure 18. The virtual exergy input due to pollutant emissions into AFF subsectors.

\subsubsection{Total Inputs}

All three immaterial inputs addressed by EEA are quantitatively superior to NREA inputs. The biggest share of energetic and material inputs reached $14 \%$ in 2012, revealing the discrepancy between immaterial and material inputs and pointing out capital and labour as the main factors of production. Environmental impact proved to be the strongest concern and quantitatively exceeded all other inputs (Figure 19). Overall values dropped 25\% due to the decrease in energy resources, capital and air emissions.

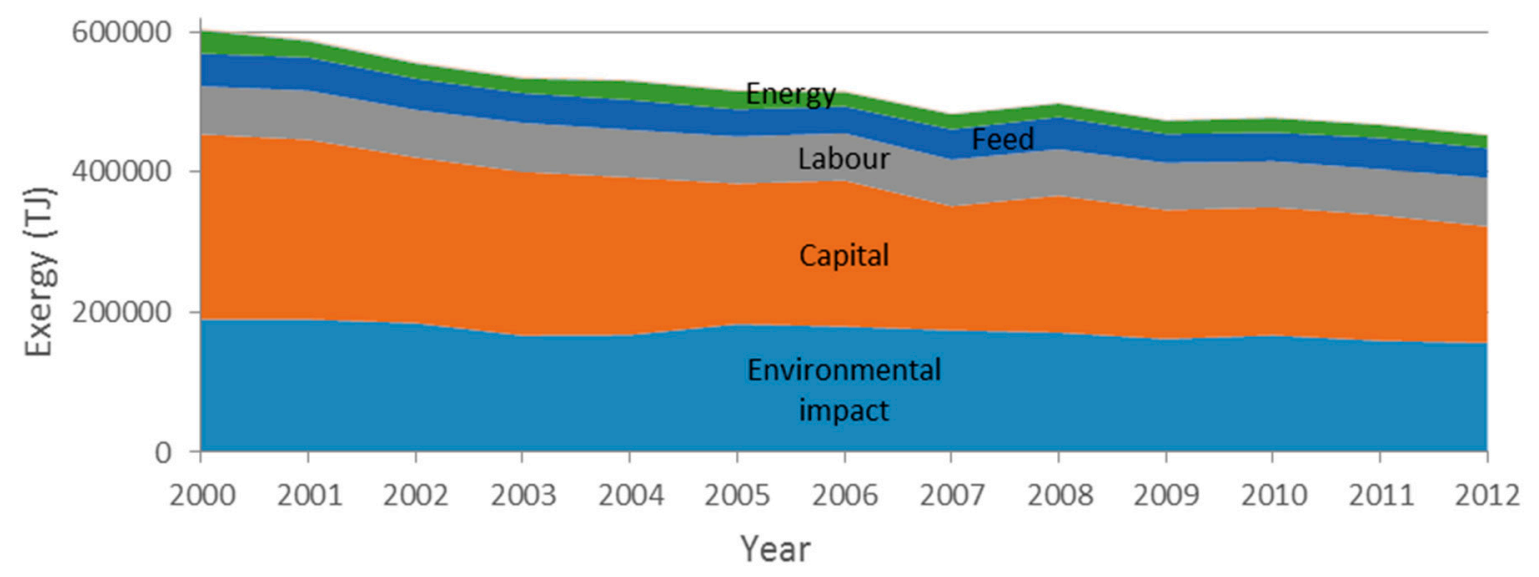

Figure 19. Extended exergy input to the AFF sector.

\subsubsection{Sector and Subsector Efficiencies}

The introduction of three highly valuable production factors to the input matrix dramatically lowered the efficiency of all AFF subsectors. The agriculture and forestry subsector increased their efficiency by $33 \%$ (from $27 \%$ in 2000 to $36 \%$ in 2012) while fishery increased its efficiency by $32 \%$ (from $2.7 \%$ in 2000 to $3.6 \%$ in 2012) (Figure 20). This improvement was mainly due to a decrease of the capital exergetic input. 


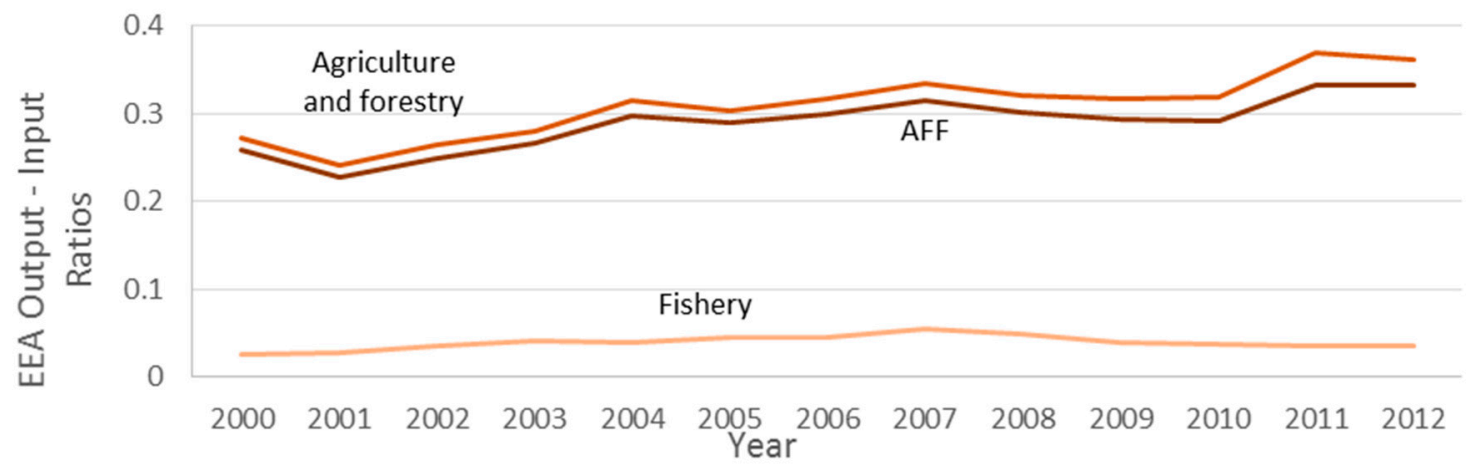

Figure 20. AFF sector and subsectors efficiencies by EEA approach.

\section{Discussion and Conclusions}

Results obtained for the Agriculture, Forestry and Fisheries (AFF) sector and subsectors, regarding the ratio of exergy outputs to inputs, using the three exergy accounting methodologies are synthesized in Figure 21. Results for the AFF sector are similar among methodologies. With the EREA approach there is a 30\% increase in the overall efficiency due to a better match between the energy carrier and the end uses. NREA presented a similar growth in overall efficiency representing the sector's return over the applied energy and matter. The EEA methodology showed the same overall tendency regarding the evolution of efficiency, although the results are clearly dominated by the capital and environmental impact. For the fisheries subsector, the results are contradictory among methodologies.

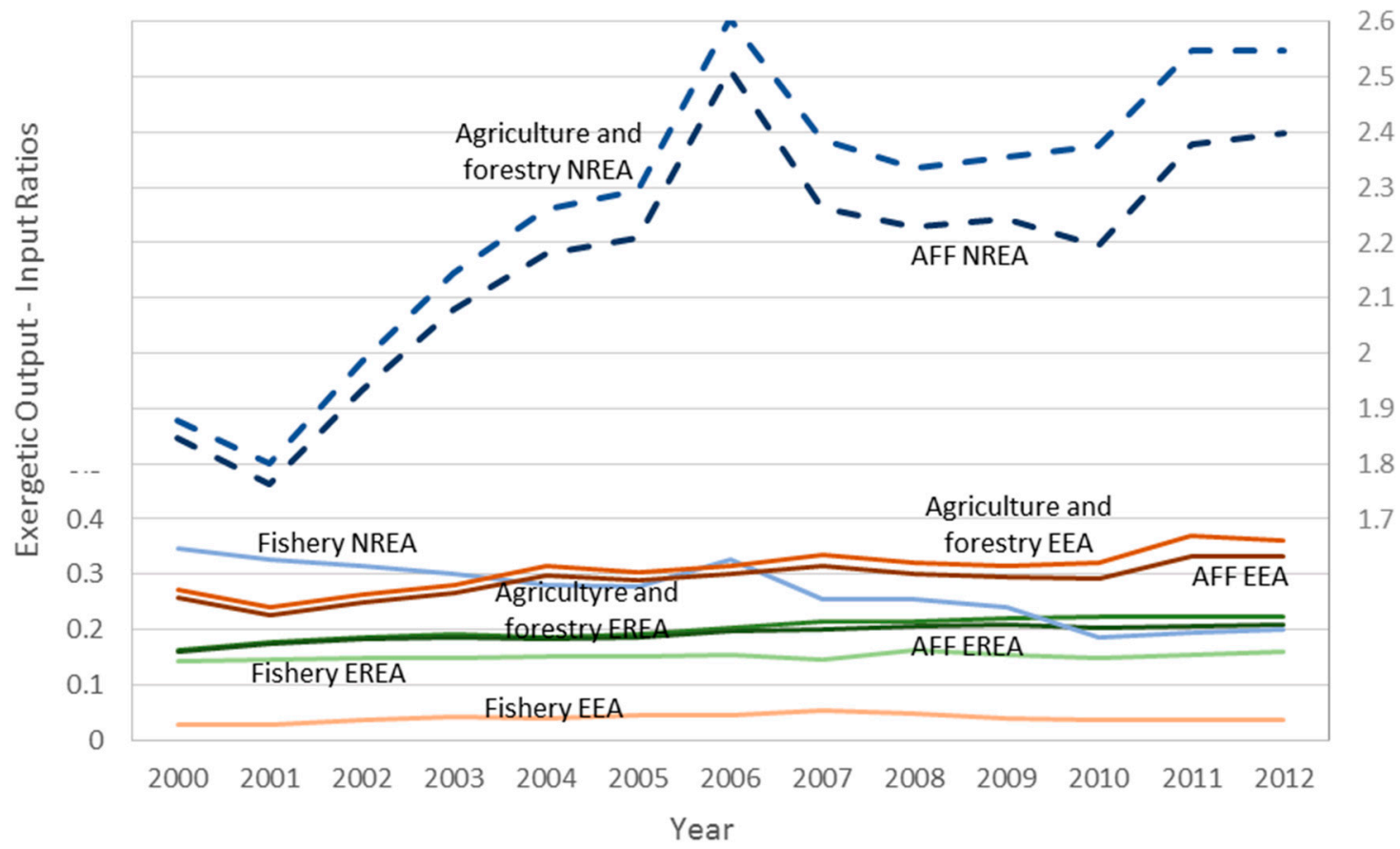

Figure 21. AFF sector and subsectors' efficiencies by methodology (full lines on the left axis and dashed lines on the right axis). EREA in shades of green, NREA in shades of blue and EEA in shades of orange.

Energy resources' exergy accounting (EREA) only addresses one type of inputs-energy carriers-to estimate the available useful exergy for its end uses and the overall efficiency. Although it estimates the actual amount of exergy that is delivered to a system function, no information regarding the output is introduced in the analysis. For Portugal, the overall efficiency reached $21 \%$ and is rapidly increasing over time due to a bigger share of the use of electricity whose efficiency is substantially 
higher, mainly for its predominant use in mechanical drives, mostly associated with irrigation systems. In fisheries, diesel fuel continues to be preponderant in fishing vessels, although with lower efficiencies. This explains the different performance levels of the two subsectors.

The natural resources exergy accounting (NREA) approach uses all energetic and physical inputs and outputs to describe a system's efficiency without any knowledge about the system's processes and resources utilization. In the present analysis, all inputs were accounted for only by their intrinsic exergies values, not by their cumulative exergy values. The exergy that has been used to transform and bring the inputs to the boundaries of the AFF sector are integrated in the other economic sectors like industry for the fertilizers and pesticides, extraction and conversion for energy carriers and tertiary and transportation for almost all. The exergy input has decreased 24\% since 2000 (Figure 13) with feed for animal husbandry representing the biggest share (68\% in 2012), followed by the energy resources. The exergy of feed is on average $140 \%$ superior to the exergy of all crops harvested, which means that Portuguese agriculture does not produce enough to support its animal husbandry. Feed does not consider green fodder, pasture, meadows and straw because these are internally produced and consumed in the sector. The output-input ratio of animal husbandry (with feed and incubation eggs as inputs, only) evolved from $26 \%$, in 2000 , to $31 \%$ in 2012 . This positive evolution indicates either a better use of feed in livestock production or a bigger share of non-accounted feed. The exergy output from the sector is mostly embedded in wood and harvested crops with wood exergy reaching a share of $71 \%$ in 2012 (Figure 11).

Although exergy is degraded, the output-input ratio of the agricultural and forestry subsectors can be higher than one (contrary to other economic sectors except extraction and conversion based on renewables) because solar radiation is not taken into account. Considering NREA, the sector's overall ratio increased more than $27 \%$ in this period being close to 2.5 in 2012, which means that for every exergy Joule that entered in the AFF sector, two and a half Joules were harvested. Agriculture and forestry performed much better than fishery (Figure 15) whose efficiency decreased 53\% since 2000 (from $43 \%$ in 2000 to $20 \%$ in 2012). This decreasing efficiency verified for fisheries and aquaculture is exclusive for the NREA methodology. While in EREA we observe a better match between the energy carrier and the end use, in NREA the total amount of nutritional values from fish caught is decreasing for each exergy unit spent on the fishery activities.

The explanation for this puzzle is revealed by looking at the ratio of the output exergy (measured by the NREA methodology) to the useful exergy (measured by the EREA methodology) which is a proxy for the efficiency of the energy services in the AFF sector (see Figure 22). Contrary to agriculture and forestry which improved the efficiency of the exergy services by 59\% (from 27 to 47 ), fishery reduced theirs to $31 \%$ of the initial value (from 5 to 1.5 ). While in the agriculture subsector each Joule of useful exergy produced 47 Joules of food in 2012, in fishery only 1.5 Joules were caught. The agriculture and forestry subsectors are less dependent on energy resources.

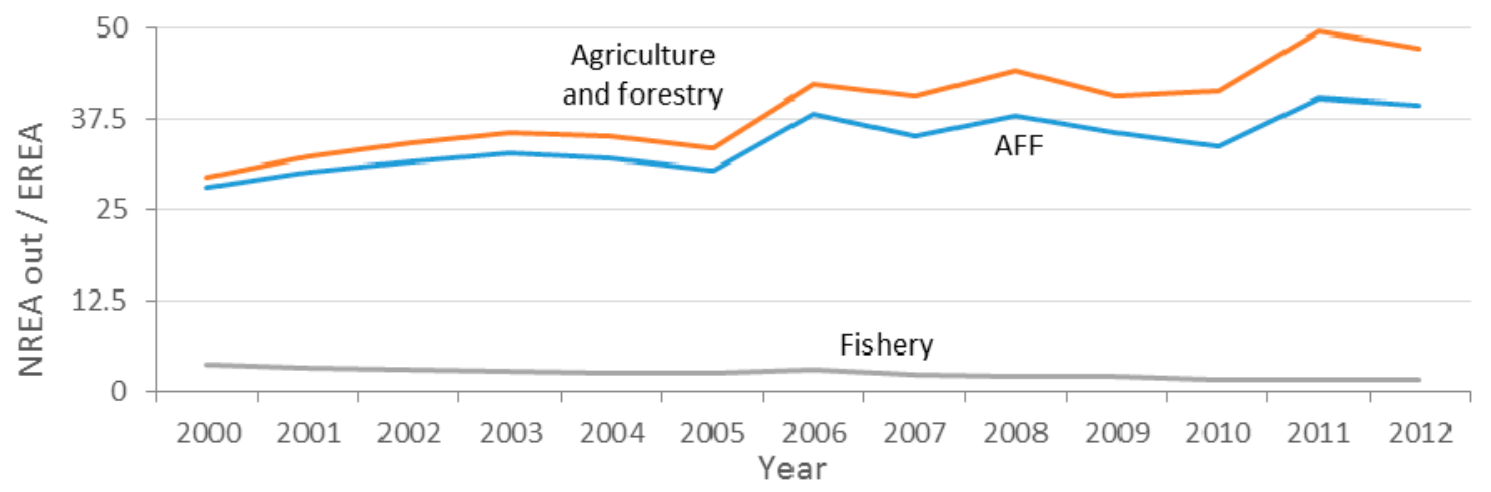

Figure 22. Ratio between output exergy from the sector and the useful exergy from energy resources. 
The efficiency of the exergy services in fisheries is the amount of fish catch per unit of useful exergy. To explain this better, we will focus on the diesel carrier, which is responsible for almost $90 \%$ of the consumption matrix (in 2012) and used for transportation services. The fish catch per useful exergy ratio is equal to the fish catch per distance travelled times the thermodynamic efficiency of the boat engine (distance travelled per unit of useful exergy). In fisheries a higher thermodynamic efficiency is not translated into higher energy services efficiency presumably because fish population is decreasing leading fishing vessels to travel more (or more often) to get the same amount of fish.

Extended exergy accounting (EEA) allows us to compare the weight of different inputs. The exergy embodied in labour, which is less than an average daily work in other sectors $(1500 \mathrm{~h}$ per year and per worker in 2012), has the same magnitude of all other material and energetic inputs taken together. Capital exergy is predominant over labour and although it is rapidly decreasing over time, it is larger than the overall exergy of outputs. Figure 18 also shows that actually, the bigger input in EEA is the environmental impact from the sector, being all three immaterial inputs seven times superior to the material ones. These results raise issues regarding the proportionality between material and immaterial inputs in the EEA methodology. By considering that the cost of labour and capital is a cumulative societal exergy and, by accounting all other inputs in its intrinsic form, the study reveals the disproportionality that results from this inconsistency. Also, measuring the capital input to the sector by all currency money (M2) minus wages creates an additional problem, because some of this money is used to buy all energetic and material inputs that entered the agricultural sector, and that were taken already into account for by their intrinsic exergies. Following the proposed methodology leads to double counting all natural resources inputs because both intrinsic exergy plus the currency money necessary to buy them are taken into account.

So, are the different exergy accounting methodologies providing consistent or contradictory results? Results provided by the EREA and NREA approaches can be contradictory but they are complementary because the EREA is focused on the thermodynamic efficiency while the NREA extends the boundary allowing the evaluation of the efficiency of the energy service. Both approaches are important in providing a realistic picture of the sectorial exergy efficiency. On the other hand, results obtained by the EEA approach are completely dominated by the exergies of capital and environmental impacts, revealing the disproportionality between material and immaterial inputs in this methodology. Improving the estimation of EEA externalities, labour and capital, for sectorial studies, remains a challenge for future studies.

We propose and apply to our case studies of the AFF sector, using the NREA and EEA approaches, methodological options to account for the renewable flows obtained from the environment, that are more adequate for sustainability assessments. While former NREA and EEA studies [19,21-30] account all crops, wood and fisheries as an input to the agricultural sector from the environment, this study acknowledges that all these flows are renewable and an output of human activities. Fish catch (excluding fish farming) is considered an extraction because no human activity helps to feed and raise the fish and excessive catches together with pollution have caused a decrease in fish population [55]. For a better assessment of sustainability, it would be important to include and correctly evaluate in NREA and EEA studies, the environmental positive impact of the carbon dioxide sequestered from atmosphere by the AFF sector because, although there is a substantial fraction of the carbon content in vegetables, fruits, crops and wood that is released after consumption, some carbon remains sequestered in living beings and wood used for veneer and saw logs.

Acknowledgments: Work financially supported by FCT/MCTES (PIDDAC) through project UID/EEA/50009/2013.

Author Contributions: Tiago Domingos provided significant comments throughout the study; Tania Sousa helped conceptually and technically with the application of the methodologies, contributed to the interpretation of the results and writing of the paper; and Ricardo Manso undertook the analysis, writing the code to manipulate datasets, and wrote most of the paper.

Conflicts of Interest: The authors declare no conflict of interest. 


\section{Appendix A. The Exergy Concept}

Exergy is measured in relation to a reference environment characterized by a temperature, $T_{0}$, a pressure $p_{0}$, and a chemical composition. When the system is in equilibrium with the environment, the system is at the "dead state" and its exergy is null.

A system or stream can have several types of mechanical energy (or exergy), depending on the relation to the surrounding environment. If it has non-zero velocity then it possesses kinetic energy and both the specific energy and exergy are given by $e x_{k}=\frac{V^{2}-V_{0}^{2}}{2}$ being $\mathrm{V}$ its velocity. It has a potential energy or exergy if it is bound to a conservative force (gravitational, elastic, electric, ... ) being the gravitational potential energy the most common. Both the specific gravitational potential energy and exergy are the same and given by $e x_{p g}=g\left(z-z_{0}\right)$ being $g$ gravitational acceleration and $z-z_{0}$ the height relative to the "dead state".

The physical exergy, which is the maximum amount of work that can be extracted by taking the resource from its initial pressure and temperature to the reference environment at $T_{0}$ and $p_{0}$, is $e x_{p h}=\left(u-u_{0}\right)+p_{0}\left(v-v_{0}\right)-T_{0}\left(s-s_{0}\right)$ [43], being $u_{0}, v_{0}$ and $s_{0}$ the specific internal energy, specific volume and specific entropy at the "dead state". All the change in internal energy of the system can be converted to work except: (1) the minimum energy that must be dissipated in the form of heat to decrease the entropy from $s$ to $s_{0}$ and (2) the minimum mechanical energy that must be used to increase the volume from $v$ to $v_{0}$.

For an open system, the physical exergy that accompanies the mass flow must take into account also the flow work and is given by $e x_{f, p h}=h-h_{0}-T_{0}\left(s-s_{0}\right)$ where $h_{0}$ is the specific enthalpy at the "dead state". As pointed out by Sciubba [23] this equation truly expresses the real attribute of exergy: the amount of useful work that can be extracted from a certain system is measured by its enthalpic content $\left(h-h_{0}\right)$ but taking into account that the system has to dissipate energy in the form of heat to get rid of entropy.

The exergy associated to heat transfer $(Q)$ is $E x_{Q}=Q\left(1-\frac{T_{0}}{T}\right)$. This exergy is obtained by a direct application of the Carnot efficiency and represents the maximum amount of work that the heat flow can produce. Finally, the chemical exergy of a substance, or resource, is the maximum work that can be obtained by taking it from $T_{0}$ and $p_{0}$ to chemical equilibrium with the reference environment. The reference environment could be the lithosphere (Earth crust) if the substance is a solid compound, the hydrosphere (water on, under and above the surface) if it is a dissolved ionic compound or the atmosphere if it is a gaseous compound. The specific chemical exergy of a compound is computed by Romero and Linares [56] as: $e x_{c h}=\sum_{i} \Delta_{f} G^{0}+\sum_{e l} n_{e l} b_{c h, e l}^{0}$ were $\Delta_{f} G^{0}$ is the standard Gibbs energy of formation, $n_{e l}$, the number of moles of element $e l$ in the compound and $b_{c h, e l}^{0}$ the standard chemical exergy of each element.

The total specific exergy of a system or resource can now be written as the sum of all components: $e x_{S}=e x_{k}+e x_{p}+e x_{p h}+e x_{c h}$. In any real or irreversible process the entropy generated multiplied by $T_{0}$ is the exergy loss during the transformation process $e x_{\text {loss }}=T_{0} \sigma$.

\section{Appendix B. Output Flows by NREA}

\section{Appendix B.1. Crops Harvested}

Harvested crops include cereals, root crops, industrial crops, fibre crops, vegetables, fruits, nuts, vineyards and olive trees. Overall nutritional energy values are obtained by multiplying each crop mass production by their specific nutritional energy. Table A1 presents all crop specific nutritional energies [46] of all products in the production database [42]. 
Table A1. Specific Nutritional Energy (SNE) in kJ/100 g for each harvested crop [46].

\begin{tabular}{|c|c|c|c|c|c|c|c|}
\hline Crop & SNE & Crop & SNE & Crop & SNE & Crop & SNE \\
\hline Almonds & 2423 & Mushrooms & 130 & Oranges & 197 & Radishes & 66 \\
\hline Apples & 218 & Eggplants & 104 & Other berries & 225 & Raspberries & 220 \\
\hline Apricots & 201 & Eggplants & 104 & Other brassicas & 150 & Red pepper & 166 \\
\hline Barley & 1473 & Figs & 310 & $\begin{array}{l}\text { Other fresh } \\
\text { vegetables }\end{array}$ & 100 & Rye and maslin & 1414 \\
\hline Beans & 368 & Garlic & 623 & Other fruits & 369 & Sour cherries & 209 \\
\hline Broad and field beans & 1377 & Hazelnuts & 2629 & Other nuts & 2170 & Strawberries & 136 \\
\hline Cabbage (white) & 103 & Kiwis & 255 & Other pulses & 354 & Sugar beet & 293 \\
\hline Carrots & 173 & Leeks & 255 & Peaches & 165 & Sunflower seed & 1289 \\
\hline Cauliflower and broccoli & 140 & Lemons and acid limes & 126 & Pears & 239 & Tomatoes & 74 \\
\hline Celeriac & 176 & Lettuces & 65 & Peas & 339 & Triticale & 1406 \\
\hline Cherries & 263 & Melons & 141 & Plums & 192 & Vineyards & 288 \\
\hline Cucumbers & 65 & & & & & & \\
\hline
\end{tabular}

From the 65 accounted products, Figure A1 presents the 13 top crops that most contributed to the annual nutritional energy production. It is important to mention that grain maize represents nearly $40 \%$ of the total, that farmers sharply decreased wheat, oats and potatoes production and opted for olive trees and tomatoes. Overall crop production decreased $20 \%$.

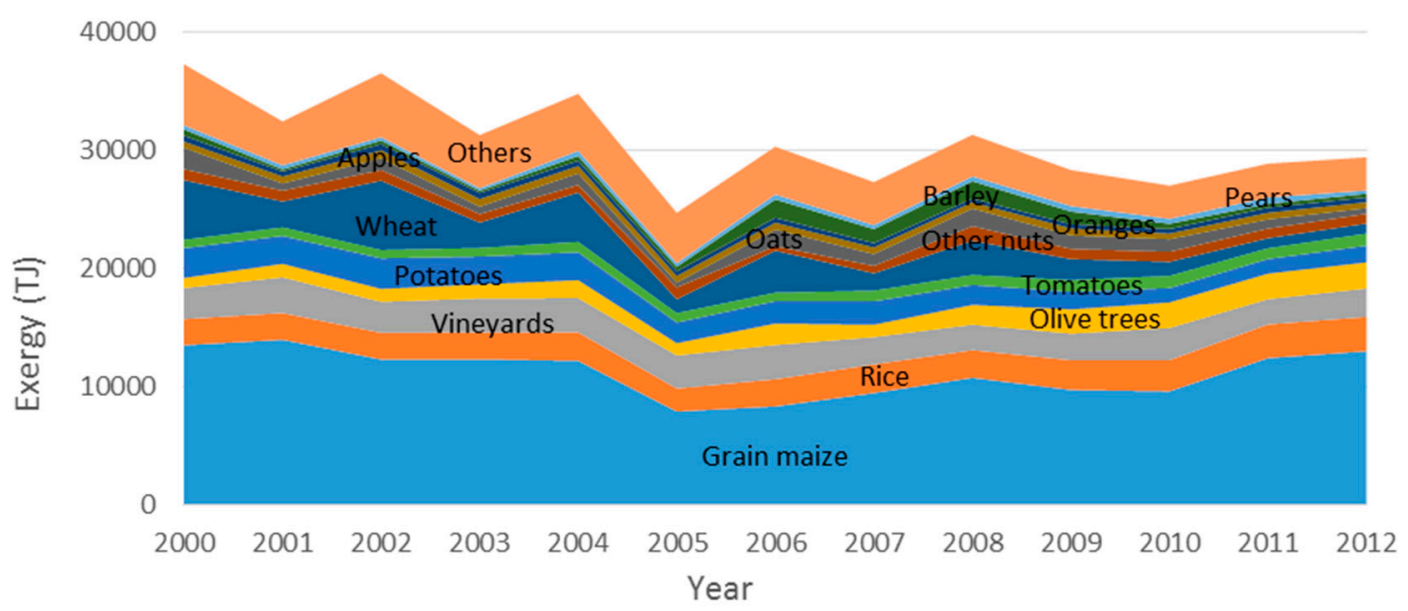

Figure A1. Nutritional energy output from crop production.

\section{Appendix B.2. Meat Slaughtering}

In the past, animal husbandry was a fundamental source of labour but in this 21st century they just represent the root of protein in our food. It's not just the high protein content and the retained nitrogen but also the specific animal amino acids and high biological value that favour their consumption. Meat production is available in mass units from the Eurostat database [42] and nutritional energy values [46] were chosen as a raw mix of meat for each animal (Table A2).

Table A2. Specific Nutritional Energy (SNE) in kJ/100 g for each slaughtered meat [46].

\begin{tabular}{cccccc}
\hline Meat & SNE & Meat & SNE & Meat & SNE \\
\hline Meat of bovine animals & 979 & Meat of rabbits & 569 & Pigmeat & 995 \\
Meat of horses, asses, mules or hinnies & 556 & Meat of sheep and goats & 1067 & Poultry meat & 979 \\
\hline
\end{tabular}


Figure A2 presents the produced energy from animal slaughtering to human consumption. Livestock is slowly increasing with pigs and poultry becoming the major intervenient. Meat of rabbits and horses is residual and can hardly be seen on the graph.

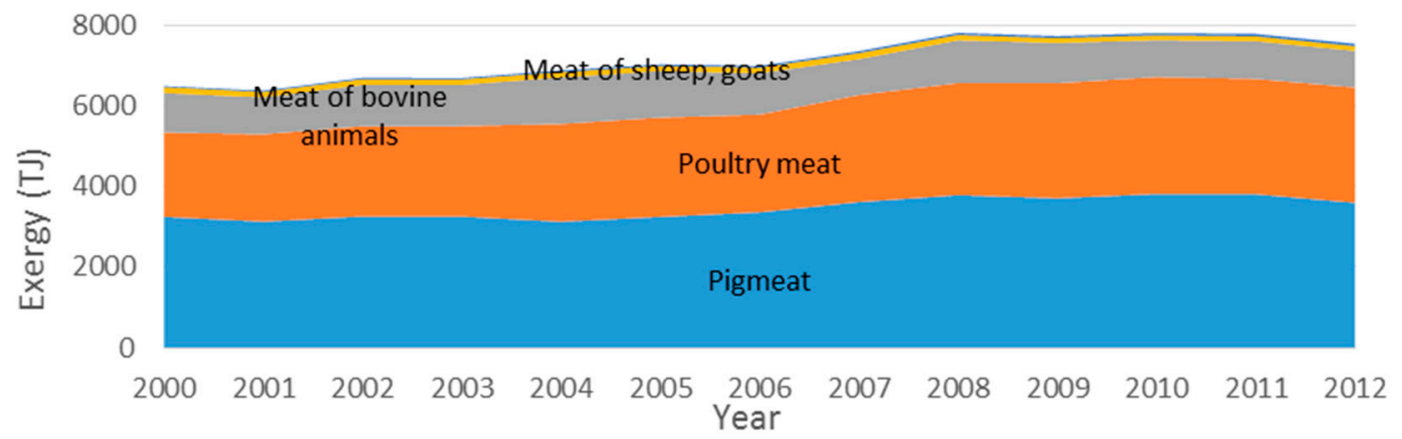

Figure A2. Nutritional energy output from meat slaughtering.

\section{Appendix B.3. Fish Catch}

Portugal, being on the southwest corner of Europe and with its long border with the Atlantic Ocean always looked at the sea as a primary source of resource extraction. As animal husbandry, fish is a fundamental source of iron and protein, has a high biological value and with the advantage of having less and better quality fat content. Fish catch is available by catching zones, fish families and individually [42].

Table A3 presents the specific nutritional energy considered for each fish, the average of their nutritional values if a family or an assumed average if in a zone. Total energy from fish catch increased until 2007 and decreased since then, mainly due to the common fisheries policy who manages fish stock for the European Union as a whole. This policy sets quotas for each member state which is allowed to catch a certain amount of each type of fish. Figure A3 shows a partial catch matrix, with the most important contributors of the Portuguese fishery. The reducing quota of sardines, a Portuguese favourite, which represented, in the past, almost $50 \%$ of the incoming energy, nowadays is relegated to second place. Upper fish fluxes of the graph represent coastal fishes; squids, cuttlefishes and octopuses; clams, cockles and arkshells; flounders, halibuts and soles and twenty more fish species families.

Table A3. Specific Nutritional Energy (SNE) in kJ/100 g for fish [46].

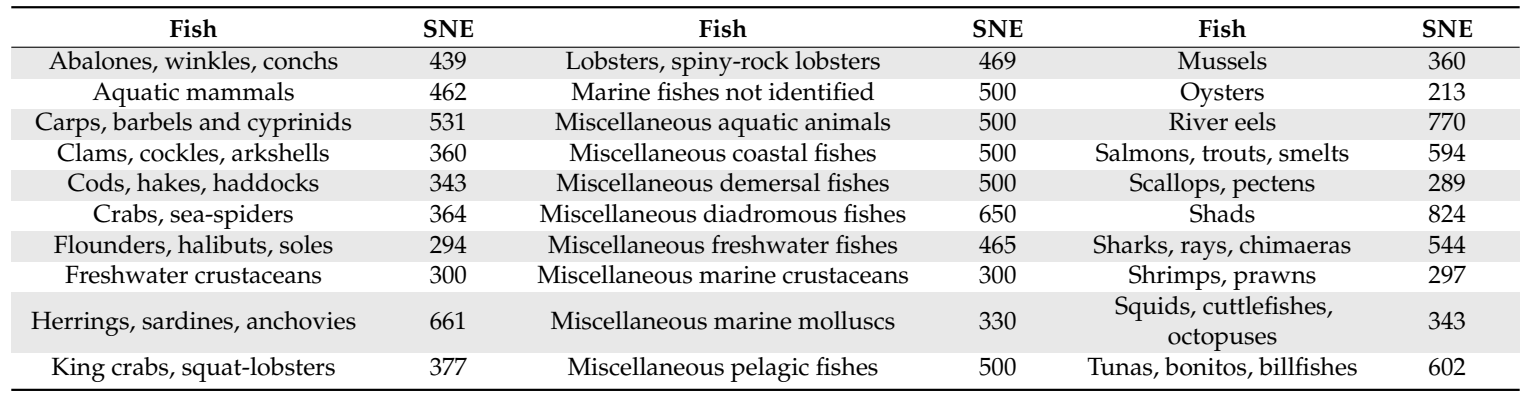




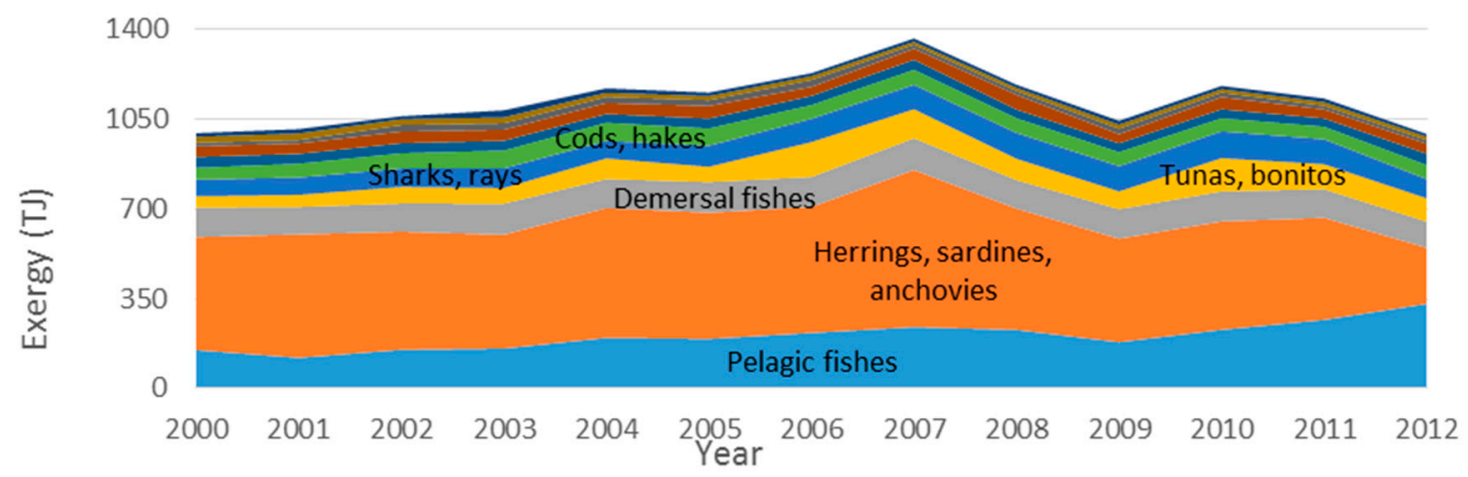

Figure A3. Nutritional energy output from fish catch.

Appendix B.4. Aquaculture

Aquaculture in Portugal is residual due to our borders with the Atlantic Ocean. Major energy supplied based on fish species is represented on Figure A4, being the total exergy not relevant to the fisheries and aquaculture subsector. Flounders, halibuts and soles are increasing its share while coastal fishes are reducing in a fluctuating production, with a small tendency to increase, over the years. Specific nutritional values are similar to the fisheries.

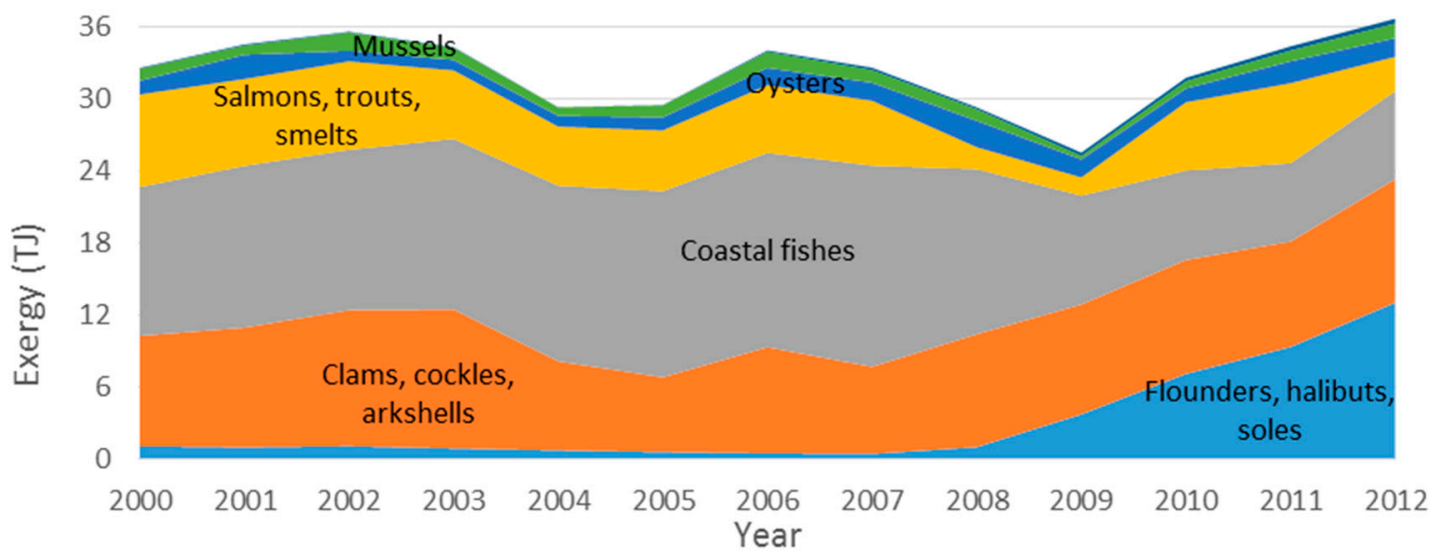

Figure A4. Nutritional energy output from aquaculture production.

\section{Appendix B.5. Milk}

Milk is a rich source of calcium and vitamin D with benefits for bones and teeth and processed into a diversity of dairy products such as cheese, butter, yogurt and cream. Specific nutritional values (Table A4) are for unprocessed milk at the producer level [46] and the production is in mass units [42].

Table A4. Specific Nutritional Energy (SNE) in kJ/100 $\mathrm{g}$ for milk [46].

\begin{tabular}{cccccc}
\hline Milk & SNE & Milk & SNE & Milk & SNE \\
\hline Cows' milk & 268 & Ewes' milk & 451 & Goats' milk & 288 \\
\hline
\end{tabular}

Milk production remained solid over the years due to dairy produced quota, a measure by the European governments to control milk production. Cow's milk represents almost the totality of milk production (Figure A5) and, as an exergy input to the society, is five times bigger than total fish catch. 


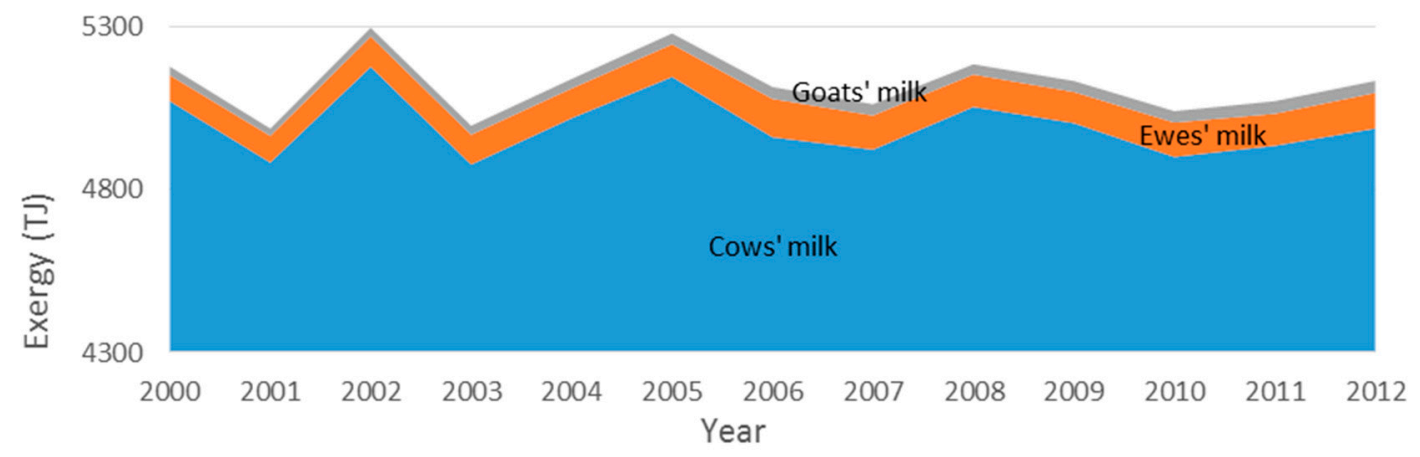

Figure A5. Nutritional energy output from collected milk.

Appendix B.6. Honey

Honey is produced by honey bees and from flowers' nectar. It is sweet due to high levels of fructose and glucose and possesses antiseptic and antibacterial properties. Overall honey production increased more than $50 \%$ through the 13 years (Figure A6). The specific nutritional energy of honey is $1272 \mathrm{~kJ}$ per $100 \mathrm{~g}$ of product [46].

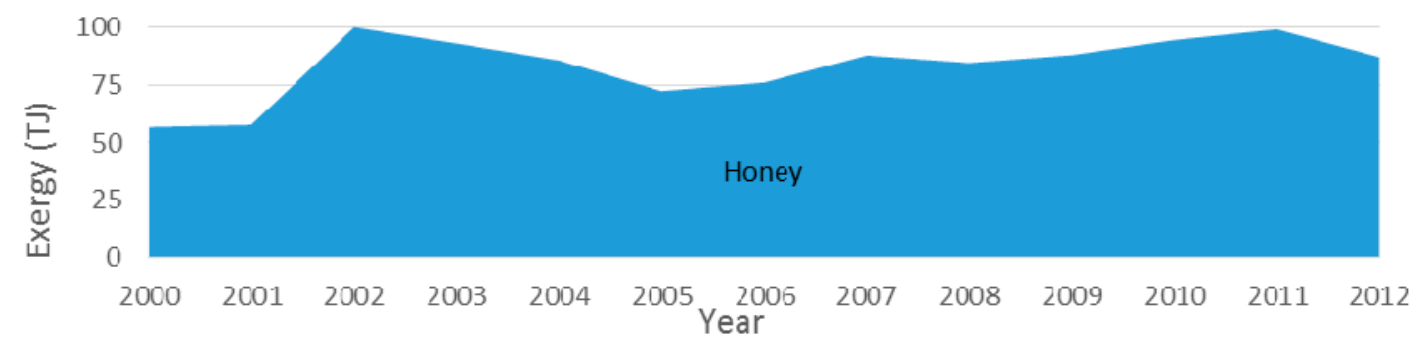

Figure A6. Nutritional energy output from produced honey.

Appendix B.7. Eggs

Eggs are one of the best sources of protein and represent the reference food in the biological value scale. Produced eggs are mainly for human food and for incubations to produce laying hens or poultry meat. It should be noted that incubation eggs are part of the produced eggs and an input to the system. Table A5 presents the specific nutritional energy of Hen eggs and an average for other bird's eggs.

Table A5. Specific Nutritional Energy (SNE) in kJ/100 g for eggs.

\begin{tabular}{cccc}
\hline Eggs & SNE & Eggs & SNE \\
\hline Hen eggs & 599 & Other bird's eggs & 776 \\
\hline
\end{tabular}

Hens' eggs are predominant in production and incubation with a stable total exergy produced (Figure A7). 


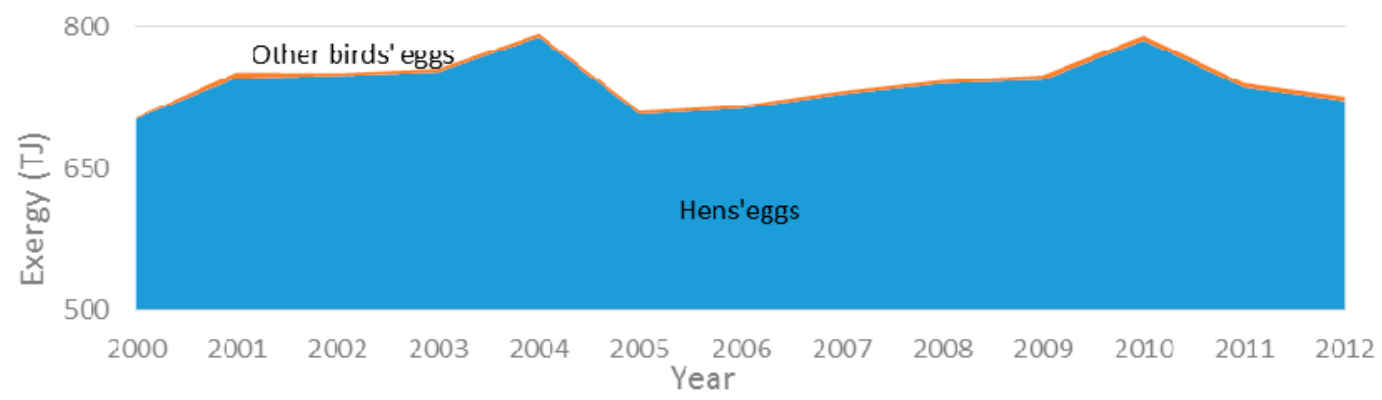

Figure A7. Nutritional energy output from produced eggs.

Appendix B.8. Wood

Forest area, in Portugal, accounts for $38 \%$ of the total area which is a high percentage compared with other European countries. Pulp and paper industry's sector represented, in 2012, 4.4\% of GDP, $8 \%$ of total industrial production and $1.2 \%$ of economy's employment [57]. Wood removals are considered as under bark with a moisture content of $20 \%$. Production is available in volume units and specific exergy values (Table A6) obtained from Dewulf et al. [52].

Table A6. Wood exergies per type of wood [52].

\begin{tabular}{cccccc}
\hline Wood & Exergy $(\mathrm{MJ} / \mathbf{k g})$ & Exergy $\left(\mathrm{GJ} / \mathrm{m}^{\mathbf{3}}\right)$ & Wood & Exergy $(\mathrm{MJ} / \mathrm{kg})$ & Exergy $\left(\mathrm{GJ} / \mathbf{m}^{\mathbf{3}}\right)$ \\
\hline Coniferous & 17.688 & 7.9596 & Non-coniferous & 17.608 & 11.4452 \\
\hline
\end{tabular}

Total industrial round wood removals had minor fluctuations over the years but the non-coniferous (hardwoods) to coniferous (softwoods) ratio increased from 1.57 in 2000 to 4.12 in 2012 (Figure A8). Coniferous wood is mainly (70\%) for saw logs and veneer logs and the remaining for pulpwood. Non-coniferous wood is more than $90 \%$ for pulpwood and the remaining for fuelwood. To highlight the importance of the forestry subsector, the total exergy collected from wood is roughly 3.5 times superior to the total exergy of harvested crops.

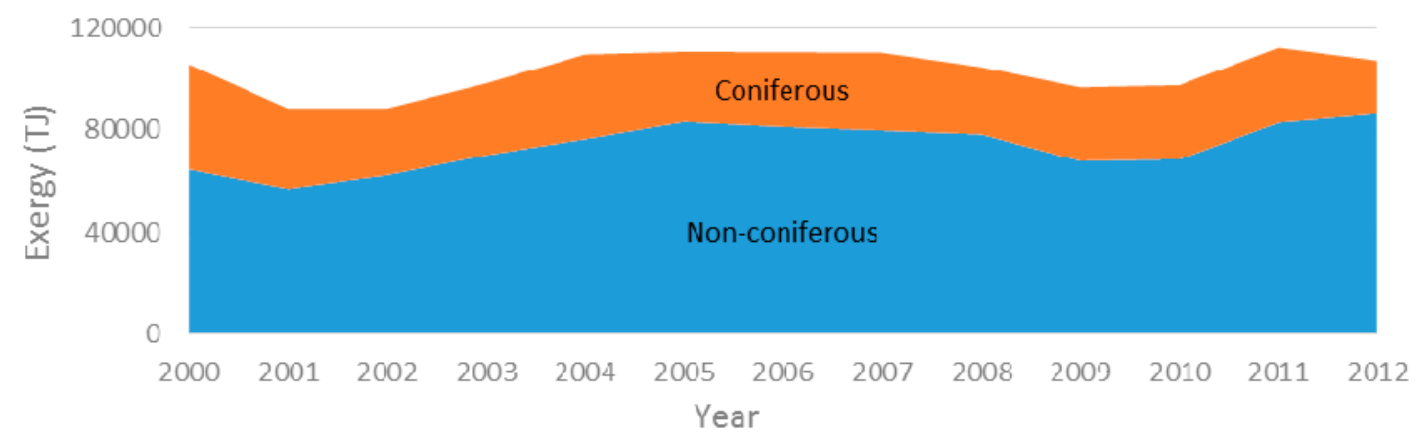

Figure A8. Exergy output from wood removals.

\section{Appendix C. Input Flows by NREA}

\section{Appendix C.1. Fertilizers}

Growing plants or trees extract nutrients from the soil that are taken away as the cultivated plants are harvested or tree fruits are removed. To allow soil productivity and enhance plant's growth, with increasing trees and plants densities, is necessary to artificially add nutrients by fertilising the soil. The fertilisers can be organic (e.g., compost, manure), bio-fertiliser (containing living microorganisms) 
or industrialized chemical compounds. The main nutrients are nitrogen $(\mathrm{N})$, phosphorus $(\mathrm{P})$ and potassium $(\mathrm{K})$ and the compounds phosphate $\left(\mathrm{P}_{2} \mathrm{O}_{5}\right)$ and potash $\left(\mathrm{K}_{2} \mathrm{O}\right)$.

The chemical exergy values (Table A7) were estimated with the corresponding chemical formula, multiplying molecular mass by the standard chemical exergy (values from [44] or alternatively [58]).

Table A7. Fertilizers' chemical exergies.

\begin{tabular}{|c|c|c|c|c|c|c|}
\hline Fertilizer & $\begin{array}{l}\text { Chemical } \\
\text { Formula }\end{array}$ & $\begin{array}{l}\text { Molecular } \\
\text { Mass g/mol }\end{array}$ & $\begin{array}{l}\text { Exergy } \\
\mathrm{kJ} / \mathrm{mol}\end{array}$ & $\begin{array}{l}\text { Exergy } \\
\mathrm{kJ} / \mathrm{kg}\end{array}$ & \multirow{4}{*}{$\begin{array}{c}\text { Alternatively } \\
{[58]}\end{array}$} & $\begin{array}{l}\text { Exergy } \\
\mathrm{kJ} / \mathrm{kg}\end{array}$ \\
\hline Potassium/Potash & $\mathrm{K}_{2} \mathrm{O}$ & 94.203 & 413.1 & 4385 & & 4400 \\
\hline Nitrogen & $\mathrm{NH}_{4} \mathrm{NO}_{3}$ & 80.04348 & 294.8 & 3682 & & 3680 \\
\hline Phosphorus/Phosphate & $\mathrm{P}_{2} \mathrm{O}_{5}$ & 141.9446 & 319.5 & 2251 & & 2700 \\
\hline
\end{tabular}

Fertilizer usage has decreased, from 2000 to 2008, to $55 \%$ of its initial value and remained constant thereafter (Figure A9). Nitrogen is the most applied fertilizer accounting nowadays for almost half of the total exergy.

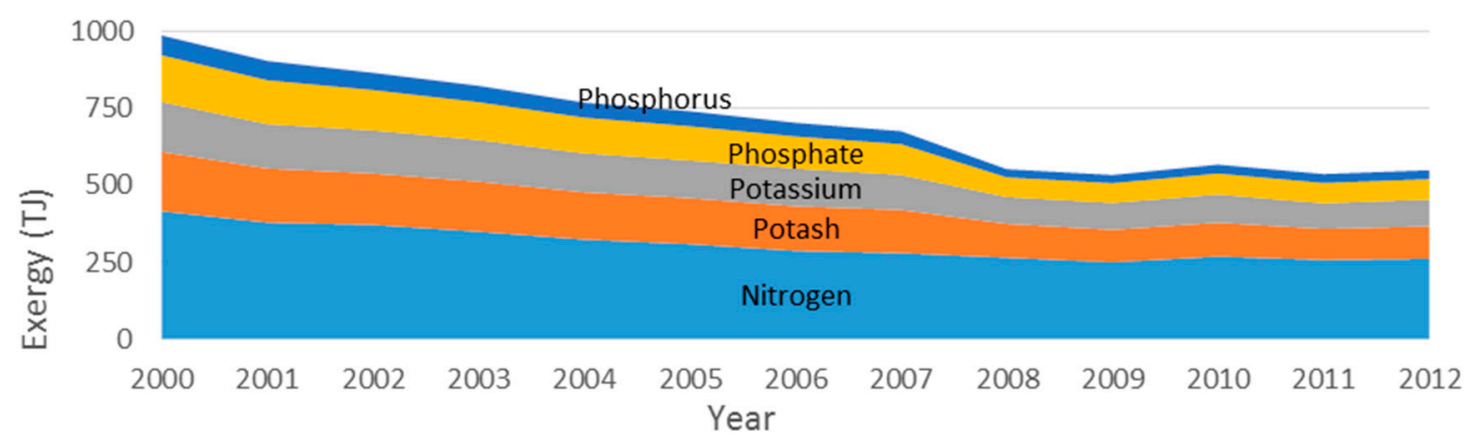

Figure A9. Exergy of fertilizers into agriculture.

\section{Appendix C.2. Pesticides}

Pesticides are biological or chemical substances that are mainly used in agriculture to protect plants from the harmful and damaging influences of microbes and plant diseases. They also kill and remove pests, insects and weeds that prevent the plants from a healthy grow. Plant grow regulators are used to protect the crop or fruit, after or before harvest, during storage and transport.

Eurostat presents data for six types of aggregated pesticides: fungicides and bactericides; herbicides, haulm destructors and moss killers; insecticides and acaricides; molluscicides; plant growth regulators and other plant protection products. Chemical exergy values were adopted from $[58,59]$ being the herbicides value the average of six known herbicides and the insecticides value the average of three insecticides active substances (Table A8). Fungicides and bactericides represent almost two thirds of total usage which decreased 20\% from 2002 onwards (Figure A10).

Table A8. Pesticides chemical exergies.

\begin{tabular}{ccc}
\hline Pesticide Type & Exergy kJ/kg & Reference \\
\hline Fungicides and bactericides & 27,900 & {$[58]$} \\
\hline Herbicides, haulm destructors and moss killers & 24,100 & \\
Insecticides and acaricides & 19,900 & {$[59]$} \\
Molluscicides, total & 19,900 & \\
Other plant protection products & 24,100 & \\
Plant growth regulators, total & 24,100 & \\
\hline
\end{tabular}




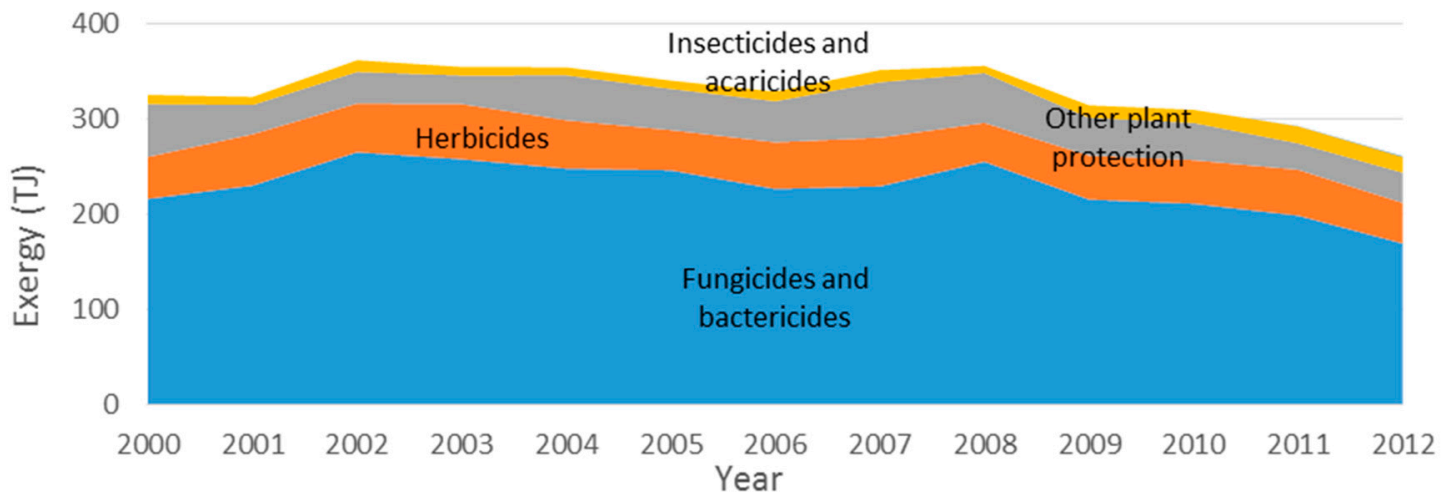

Figure A10. Exergy of pesticides into agriculture.

\section{Appendix C.3. Seeds}

As harvested cereals, roots or vegetables leave the soil new seeds must be planted. These seeds are part of the collected crops and will origin new plants to be harvested. Seeds used in agriculture are available in mass units for each plant type [45] and specific exergy values presented in Table A9. Figure A11 exhibits the top products that were used as seeds. Seeds follow the trend of harvest, as expected. The ratio of harvests to seed exergies exceeds 30 .

Table A9. Specific Nutritional Energy (SNE) in kJ/100 g for seeds [46].

\begin{tabular}{cccccccc}
\hline Seed & SNE & Seed & SNE & Seed & SNE & Seed & SNE \\
\hline Barley & 1473 & Cow peas, dry & 1432 & Oats & 1628 & Sesame seed & 2399 \\
Beans, dry & 1427 & Grain, mixed & 1455 & Oilseeds & 1800 & Sorghum & 1377 \\
Broad and horse beans & 1436 & Groundnuts & 1733 & Peas, dry & 1448 & Soybeans & 614 \\
Buckwheat & 1381 & Hempseed & 1800 & Poppy seed & 2231 & Sunflower seed & 1289 \\
Cabbages and brassicas & 150 & Lentils & 1448 & Potatoes & 321 & Taro (cocoyam) & 360 \\
Canary seed & 1624 & Linseed & 2076 & Pulses & 1423 & Triticale & 1406 \\
Castor oil seed & 1800 & Lupins & 1633 & Rapeseed & 2068 & Vegetables, fresh & 150 \\
Cereals & 1455 & Maize & 1527 & Rice, paddy & 1172 & Vetches & 1360 \\
Chick peas & 1499 & Millet & 1582 & Rye & 1414 & Wheat & 1418 \\
Cottonseed & 1059 & Mustard seed & 1963 & Safflower seed & 1314 & Yams & 422 \\
\hline
\end{tabular}

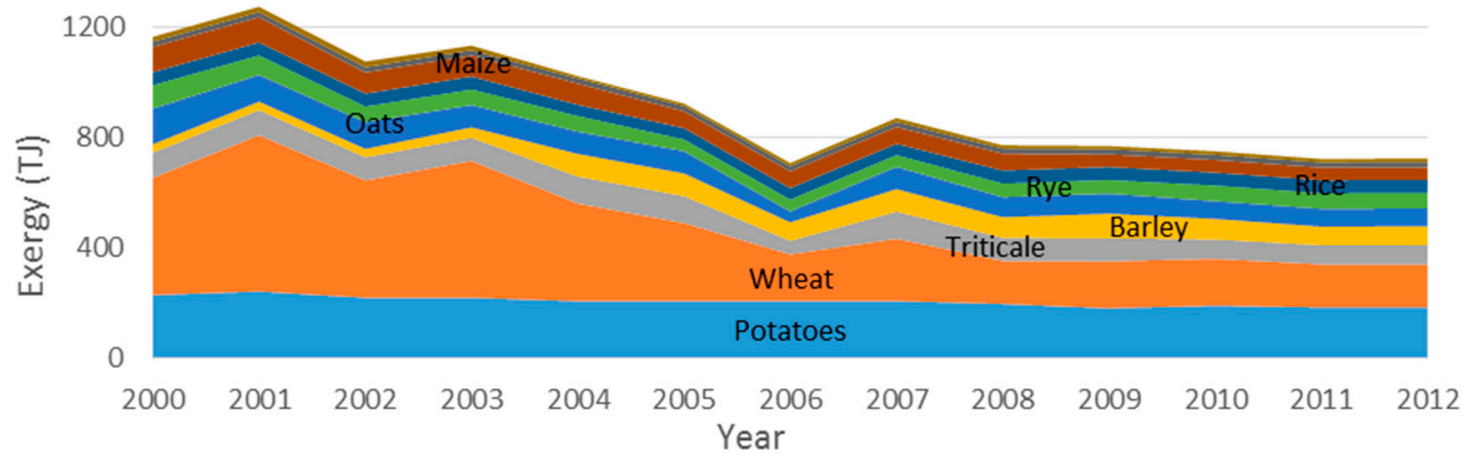

Figure A11. Nutritional energy of seeds into crop production.

\section{Appendix C.4. Feed}

Animal feed represents food given to animals. Green plants that animals forage are not accounted as input to animal husbandry nor as an output because they never exit the sector. Feed used in agriculture is available in mass units for each of the constituents [45] and specific exergy values taken from [46,48] (Table A10). 
Table A10. Specific Nutritional Energy (SNE) in kJ/100 g for feed components $[46,48]$.

\begin{tabular}{cccccccc}
\hline Feed Product & SNE & Feed Product & SNE & Feed Product & SNE & Feed Product & SNE \\
\hline Apples & 218 & Fats, Animals, Raw & 3257 & Oilcrops Other & 1639 & Rye & 1414 \\
Aquatic Plants & 180 & Fish Body Oil & 3776 & Olive Oil & 3700 & Sesame seed & 2399 \\
Bananas & 371 & Fish, Liver Oil & 3776 & Onions & 166 & Sesameseed Oil & 3700 \\
Barley & 1473 & Freshwater Fish & 400 & Palm kernels & 2152 & Sorghum & 1377 \\
Beans & 368 & Fruits, Other & 203 & Peas & 339 & Soyabean Oil & 3700 \\
Butter, Ghee & 3001 & Groundnuts & 1733 & Pelagic Fish & 400 & Soyabeans & 614 \\
Cassava & 667 & Maize & 1527 & Potatoes & 321 & Sugar beet & 293 \\
Cephalopods & 343 & Marine Fish Other & 400 & Poultry Meat & 979 & Sugar cane & 135 \\
Cereals Other & 1488 & Meat, Other & 858 & Pulses & 354 & Sunflower seed & 1289 \\
Coconuts & 770 & Milk-Excluding Butter & 353 & Rape and Mustard Oil & 3700 & Sweet potatoes & 359 \\
Cottonseed & 1059 & Millet & 1582 & Rape and Mustardseed & 2068 & Tomatoes & 74 \\
Crustaceans & 300 & Oats & 1628 & Rice & 1548 & Vegetables Other & 226 \\
Demersal Fish & 400 & Offals, Edible & 486 & Roots Other & 449 & Wheat & 1418 \\
Eggs & 682 & Oilcrops Oil, Other & 3700 & & & \\
\hline
\end{tabular}

It is important to notice that the exergetic contents of maize used to feed animals and total harvests are of the same magnitude (see Figure A12) which explains the need to import the majority of cereals used to produce feed. From the 54 accounted products used to produce feed, maize represented $57 \%$ of all inputs in 2000 and $69 \%$ in 2012. Total exergy over time has a slight tendency to decrease, reducing $10 \%$ from 2000 to 2012.

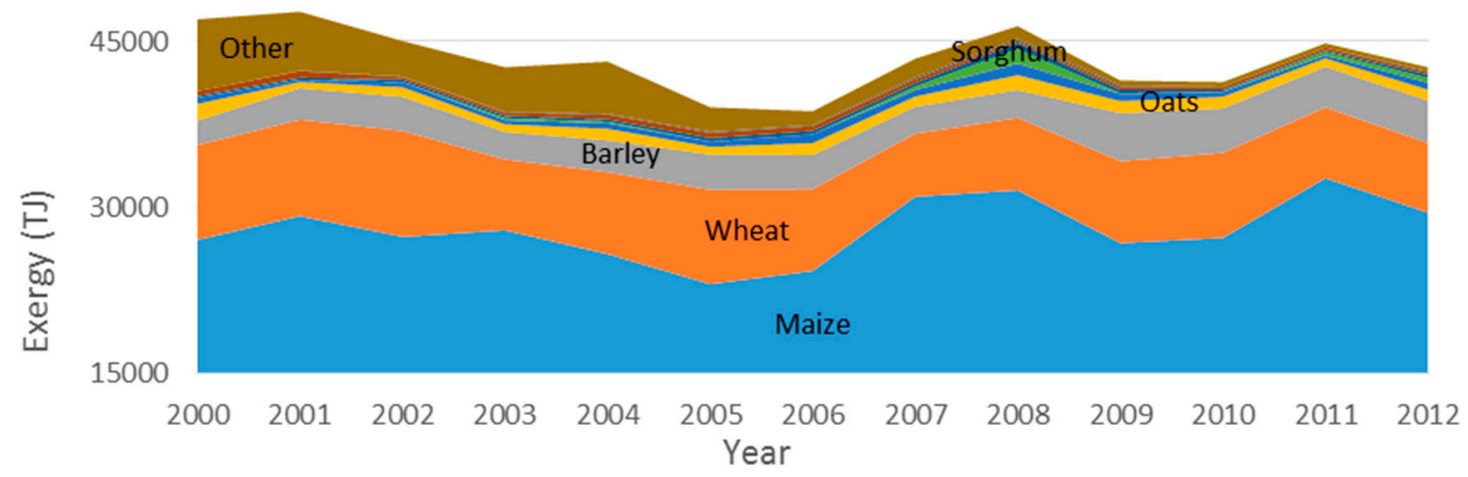

Figure A12. Nutritional energy of feed into animal husbandry.

\section{Appendix C.5. Incubation eggs}

Poultry meat increased $40 \%$ over 13 years and consequently the incubated eggs. Part of the produced eggs is for incubations which ranged from $10 \%$ in 2000 to over 15\% in 2012. Exergy on incubations increase 75\% over the considered years (Figure A13). Data from the Eurostat database [42] is in number of egg units and, in order to measure the mass content, the egg's average mass [60] was multiplied by the respective number of eggs into incubation (Table A11).

Table A11. Specific Nutritional Energy (SNE) in kJ/100 g [46] and average mass for eggs [60].

\begin{tabular}{ccccccccc}
\hline Eggs & SNE & Mass $(g)$ & Eggs & SNE & Mass (g) & Eggs & SNE & Mass (g) \\
\hline Ducks' eggs & 776 & 70 & Guinea fowl eggs & 663 & 9 & Turkey eggs & 716 & 79 \\
Geese eggs & 775 & 144 & Hens'eggs & 599 & 53 & & \\
\hline
\end{tabular}




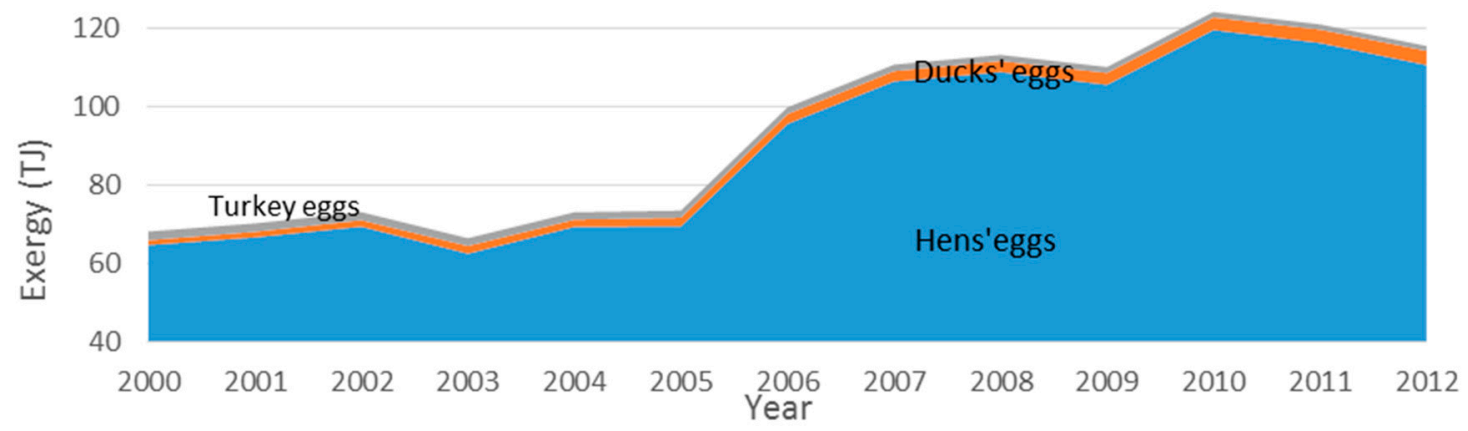

Figure A13. Nutritional energy of incubation eggs.

\section{Appendix D. Additional Data}

Missing data is relevant on HDI values (54\%) and eggs for incubation which represented $40 \%$, mainly on non-relevant fluxes of turkey and duck's eggs. There was also missing data on pesticides (about $15 \%)$, feed $(7 \%)$, crops $(5 \%)$, meat $(4 \%)$, energy $(3 \%)$, aquaculture $(2 \%)$ and fish catch $(1 \%)$. All other fluxes had no missing data.

Table A12 presents the HDI values for Portugal where the interpolated data is in italic. Table A13 presents the price deflator in a 2010 reference from which all monetary values were multiplied, since all were downloaded at current prices. Table A14 presents the population and workers allocated to each AFF subsector and Table A15 all the monetary values of GVA, M2 and wages.

Table A12. HDI values for Portugal (italic values interpolated).

\begin{tabular}{ccccccccccccc}
\hline $\mathbf{2 0 1 2}$ & $\mathbf{2 0 1 1}$ & $\mathbf{2 0 1 0}$ & $\mathbf{2 0 0 9}$ & $\mathbf{2 0 0 8}$ & $\mathbf{2 0 0 7}$ & $\mathbf{2 0 0 6}$ & $\mathbf{2 0 0 5}$ & $\mathbf{2 0 0 4}$ & $\mathbf{2 0 0 3}$ & $\mathbf{2 0 0 2}$ & $\mathbf{2 0 0 1}$ & $\mathbf{2 0 0 0}$ \\
\hline 0.8220 & 0.8191 & 0.8159 & 0.8103 & 0.8053 & 0.8029 & 0.7992 & 0.7900 & 0.7917 & 0.7880 & 0.7842 & 0.7805 & 0.7800 \\
\hline
\end{tabular}

Table A13. Price deflator values referenced to 2010.

\begin{tabular}{ccccccccccccc}
\hline $\mathbf{2 0 1 2}$ & $\mathbf{2 0 1 1}$ & $\mathbf{2 0 1 0}$ & $\mathbf{2 0 0 9}$ & $\mathbf{2 0 0 8}$ & $\mathbf{2 0 0 7}$ & $\mathbf{2 0 0 6}$ & $\mathbf{2 0 0 5}$ & $\mathbf{2 0 0 4}$ & $\mathbf{2 0 0 3}$ & $\mathbf{2 0 0 2}$ & $\mathbf{2 0 0 1}$ & $\mathbf{2 0 0 0}$ \\
\hline $\mathbf{9 9 . 3 3 3}$ & 99.730 & 100 & 99.360 & $\mathbf{9 8 . 2 8 3}$ & 96.604 & 93.809 & 90.913 & 87.984 & 85.925 & 83.068 & 79.714 & $\mathbf{7 6 . 8 5 9}$ \\
\hline
\end{tabular}

Table A14. Population and workers allocated to each AFF subsector (thousands).

\begin{tabular}{|c|c|c|c|c|c|c|c|c|c|c|c|c|c|}
\hline Workers & 2012 & 2011 & 2010 & 2009 & 2008 & 2007 & 2006 & 2005 & 2004 & 2003 & 2002 & 2001 & 2000 \\
\hline Population & 10,514 & 10,557 & 10,573 & 10,568 & 10,558 & 10,542 & 10,522 & 10,503 & 10,483 & 10,458 & 10,419 & 10,362 & 10,289 \\
\hline Agriculture & 497.2 & 489.8 & 508.8 & 534.3 & 542.2 & 546.2 & 556.9 & 557.3 & 566.7 & 591 & 585.9 & 604.3 & 584.6 \\
\hline Forestry & 10.9 & 10.9 & 10.6 & 10.7 & 12.0 & 11.8 & 11.8 & 11.7 & 11.7 & 11.8 & 11.7 & 11.9 & 11.6 \\
\hline Fishery & 14.0 & 14.3 & 14.0 & 13.9 & 14.4 & 14.3 & 15.0 & 14.9 & 15.0 & 15.0 & 14.8 & 15.0 & 14.8 \\
\hline
\end{tabular}

Table A15. Monetary values of all sectors and AFF sector at constant 2010 prices (Billion Euro for Total values and Million Euro for subsectorial values). Total-All sectors, GVA—gross value added, Wages-Compensation of employees.

\begin{tabular}{cccccccccccccc}
\hline Monetary Values & $\mathbf{2 0 1 2}$ & $\mathbf{2 0 1 1}$ & $\mathbf{2 0 1 0}$ & $\mathbf{2 0 0 9}$ & $\mathbf{2 0 0 8}$ & $\mathbf{2 0 0 7}$ & $\mathbf{2 0 0 6}$ & $\mathbf{2 0 0 5}$ & $\mathbf{2 0 0 4}$ & $\mathbf{2 0 0 3}$ & $\mathbf{2 0 0 2}$ & $\mathbf{2 0 0 1}$ & $\mathbf{2 0 0 0}$ \\
\hline Total GVA & 141 & 149 & 151 & 149 & 151 & 151 & 147 & 146 & 148 & 145 & 147 & 147 & 145 \\
Total M2 & 163 & 174 & 173 & 170 & 179 & 163 & 159 & 157 & 150 & 147 & 147 & 153 & 151 \\
Agriculture GVA & 2224 & 2184 & 2413 & 2440 & 2497 & 2538 & 2887 & 2891 & 3272 & 3260 & 3337 & 3655 & 3869 \\
Agriculture M2 & 2585 & 2537 & 2765 & 2776 & 2946 & 2735 & 3113 & 3097 & 3312 & 3294 & 3327 & 3784 & 4019 \\
Agriculture Wages & 817 & 756 & 787 & 784 & 782 & 787 & 778 & 795 & 780 & 775 & 768 & 825 & 823 \\
Forestry GVA & 647 & 689 & 657 & 613 & 662 & 682 & 708 & 716 & 785 & 814 & 893 & 893 & 841 \\
Forestry M2 & 752 & 800 & 753 & 697 & 782 & 735 & 763 & 767 & 795 & 822 & 890 & 924 & 874 \\
Forestry Wages & 108 & 104 & 102 & 98 & 105 & 101 & 100 & 102 & 100 & 100 & 99 & 106 & 106 \\
Fishery GVA & 399 & 412 & 396 & 378 & 419 & 418 & 413 & 416 & 459 & 459 & 476 & 509 & 521 \\
Fishery M2 & 464 & 478 & 454 & 430 & 494 & 450 & 445 & 446 & 464 & 464 & 474 & 527 & 541 \\
Fishery Wages & 170 & 160 & 156 & 160 & 175 & 178 & 176 & 179 & 176 & 175 & 173 & 186 & 186 \\
\hline
\end{tabular}




\section{References}

1. Pezzey, J.C.V. Sustainability constraints versus "optimality" versus intertemporal concern, and axioms versus data. Land Econ. 1997, 73, 448. [CrossRef]

2. Imperatives, S. Report of the World Commission on Environment and Development: Our Common Future; Oxford University Press: Oxford, UK, 1987.

3. National Research Council. Toward Sustainable Agricultural Systems in the 21st Century; National Academies Press: Washington, DC, USA, 2010.

4. Dewulf, J.; Van Langenhove, H.; Muys, B.; Bruers, S.; Bakshi, B.R.; Grubb, G.F.; Paulus, D.M.; Sciubba, E. Exergy: Its Potential and Limitations in Environmental Science and Technology. Environ. Sci. Technol. 2008, 42, 2221-2232. [CrossRef] [PubMed]

5. Reistad, G. Available Energy Conversion and Utilization in the United States. ASME Trans. Ser. J. Eng. Power 1975, 97, 429-434. [CrossRef]

6. Wall, G. Exergy: A Useful Concept; TH: Göteborg, Sweden, 1986.

7. Sciubba, E. Beyond thermoeconomics? The concept of Extended Exergy Accounting and its application to the analysis and design of thermal systems. Exergy Int. J. 2001, 1, 68-84.

8. Rocco, M.V.; Colombo, E.; Sciubba, E. Advances in exergy analysis: A novel assessment of the Extended Exergy Accounting method. Appl. Energy 2014, 113, 1405-1420. [CrossRef]

9. Szargut, J. Analysis of cumulative exergy consumption. Int. J. Energy Res. 1987, 11, 541-547. [CrossRef]

10. Dincer, I.; Hussain, M.M.; Al-Zaharnah, I. Energy and exergy utilization in agricultural sector of Saudi Arabia. Energy Policy 2005, 33, 1461-1467. [CrossRef]

11. Utlu, Z.; Hepbasli, A. Assessment of the energy and exergy utilization efficiencies in the Turkish agricultural sector. Int. J. Energy Res. 2006, 30, 659-670. [CrossRef]

12. Ghandoor, A.A.; Jaber, J.O. Analysis of energy and exergy utilisation of Jordan's agricultural sector. Int. J. Exergy 2009, 6, 491. [CrossRef]

13. Avara, A.; Karami, M. Energy and exergy efficiencies in agricultural and utility sectors of Iran compared with other countries. In Proceedings of the 2010 2nd International Conference on Mechanical and Electrical Technology (ICMET), Singapore, 10-12 September 2010; pp. 6-10.

14. Ahamed, J.U.; Saidur, R.; Masjuki, H.H.; Mekhilef, S.; Ali, M.B.; Furqon, M.H. An application of energy and exergy analysis in agricultural sector of Malaysia. Energy Policy 2011, 39, 7922-7929. [CrossRef]

15. Chen, G.Q.; Jiang, M.M.; Yang, Z.F.; Chen, B.; Ji, X.; Zhou, J.B. Exergetic assessment for ecological economic system: Chinese agriculture. Ecol. Model. 2009, 220,397-410. [CrossRef]

16. Hoang, V.-N.; Alauddin, M. Analysis of agricultural sustainability: A review of exergy methodologies and their application in OECD countries. Int. J. Energy Res. 2011, 35, 459-476. [CrossRef]

17. Serrenho, A.C.; Warr, B.; Sousa, T.; Ayres, R.U.; Domingos, T. Structure and dynamics of useful work along the agriculture-industry-services transition: Portugal from 1856 to 2009. Struct. Chang. Econ. Dyn. 2016, 36, 1-21. [CrossRef]

18. Guevara, Z.; Sousa, T.; Domingos, T. Insights on Energy Transitions in Mexico from the Analysis of Useful Exergy 1971-2009. Energies 2016, 9, 488. [CrossRef]

19. Wall, G. Exergy conversion in the Swedish society. Resour. Energy 1987, 9, 55-73. [CrossRef]

20. Gong, M.; Wall, G. Exergy Analysis of the Supply of Energy and Material Resources in the Swedish Society. Energies 2016, 9, 707. [CrossRef]

21. Wall, G. Exergy conversion in the Japanese society. Energy 1990, 15, 435-444. [CrossRef]

22. Wall, G.; Sciubba, E.; Naso, V. Exergy use in the Italian society. Energy 1994, 19, 1267-1274. [CrossRef]

23. Sciubba, E.; Bastianoni, S.; Tiezzi, E. Exergy and extended exergy accounting of very large complex systems with an application to the province of Siena, Italy. J. Environ. Manag. 2008, 86, 372-382. [CrossRef] [PubMed]

24. Gasparatos, A.; El-Haram, M.; Horner, M. Assessing the sustainability of the UK society using thermodynamic concepts: Part 2. Renew. Sustain. Energy Rev. 2009, 13, 956-970. [CrossRef]

25. Chen, G.Q.; Chen, B. Extended-exergy analysis of the Chinese society. Energy 2009, 34, 1127-1144. [CrossRef]

26. Zhang, B.; Chen, G.Q. Physical sustainability assessment for the China society: Exergy-based systems account for resources use and environmental emissions. Renew. Sustain. Energy Rev. 2010, 14, 1527-1545. [CrossRef] 
27. Dai, J.; Chen, B. Extended exergy-based ecological accounting of China during 2000-2007. Procedia Environ. Sci. 2011, 5, 87-95. [CrossRef]

28. Dai, J.; Fath, B.; Chen, B. Constructing a network of the social-economic consumption system of China using extended exergy analysis. Renew. Sustain. Energy Rev. 2012, 16, 4796-4808. [CrossRef]

29. Chen, B.; Dai, J.; Sciubba, E. Ecological accounting for China based on extended exergy. Renew. Sustain. Energy Rev. 2014, 37, 334-347. [CrossRef]

30. Bligh, D.C.; Ugursal, V.I. Extended exergy analysis of the economy of Nova Scotia, Canada. Energy 2012, 44, 878-890. [CrossRef]

31. Sousa, T.; Brockway, P.E.; Cullen, J.M.; Henriques, S.T.; Miller, J.; Serrenho, A.C.; Domingos, T. The need for robust, consistent methods in societal exergy accounting. Ecol. Econ. 2017, 141, 11-21. [CrossRef]

32. Sciubba, E.; Wall, G. A brief commented history of exergy from the beginnings to 2004. Int. J. Thermodyn. 2007, 10, 1-26.

33. Department of Energy. Draft 2012 Integrated Energy Planning Report-Annexure A-Technical Report; Department of Energy: Pretoria, South Africa, 2012.

34. Palma, M.; Sousa, T.; Guevara, Z. How Much Detail Should We Use to Compute Societal Aggregated Exergy Efficiencies? Energies 2016, 9, 364. [CrossRef]

35. Ayres, R.U.; Warr, B. Accounting for growth: The role of physical work. Struct. Change Econ. Dyn. 2005, 16, 181-209. [CrossRef]

36. Sciubba, E. A revised calculation of the econometric factors $\alpha$ - and $\beta$ for the Extended Exergy Accounting method. Ecol. Model. 2011, 222, 1060-1066. [CrossRef]

37. Human Development Index (HDI). Human Development Reports. Available online: http://hdr.undp.org/ en/content/human-development-index-hdi (accessed on 18 September 2014).

38. Seckin, C.; Sciubba, E.; Bayulken, A.R. Extended exergy analysis of Turkish transportation sector. J. Clean. Prod. 2013, 47, 422-436. [CrossRef]

39. European central Bank. Eurosystem statistics. Available online: https://www.ecb.europa.eu/stats/money_ credit_banking/monetary_aggregates/html/hist_content.en.html (accessed on 13 June 2015).

40. Kotas, T.J. The Exergy Method of Thermal Plant Analysis; Butterworths: London, UK, 1985.

41. Milia, D.; Sciubba, E. Exergy-based lumped simulation of complex systems: An interactive analysis tool. Energy 2006, 31, 100-111. [CrossRef]

42. Database-Eurostat. Available online: http:/ / ec.europa.eu/eurostat/data/database (accessed on 10 January 2015).

43. Szargut, J.; Morris, D.R.; Steward, F.R. Exergy Analysis of Thermal, Chemical, and Metallurgical Processes; Hemisphere: New York, NY, USA, 1988.

44. Szargut, J. Exergy Method: Technical and Ecological Applications; WIT Press: Boston, MA, USA, 2005.

45. FAOSTAT. Available online: http://www.fao.org/faostat/en/\#home (accessed on 23 January 2015).

46. US Department of Agriculture; Agricultural Research Service; Nutrient Data Laboratory. USDA National Nutrient Database for Standard Reference, Release 27; USDA: Washington, DC, USA, 2014.

47. EUROPA-Economic and Financial Affairs-Indicators -AMECO database. Available online: http://ec. europa.eu/economy_finance/ameco/user/serie/SelectSerie.cfm (accessed on 13 March 2015).

48. ESS: Nutritive Factors. Available online: http://www.fao.org/economic/the-statistics-division-ess/ publications-studies/publications/nutritive-factors/en/ (accessed on 11 July 2015).

49. Food and Agriculture Organization of the United Nations. Food Energy-Methods of Analysis and Conversion Factors; Food and Agriculture Organization of the United Nations: Rome, Italy, 2003.

50. Koester, U.; Empen, J.; Holm, T. Food Losses and Waste in Europe and Central Asia; Food and Agriculture Organization of the United Nations: Rome, Italy, 2013.

51. Seckin, C.; Sciubba, E.; Bayulken, A.R. An application of the extended exergy accounting method to the Turkish society, year 2006. Energy 2012, 40, 151-163. [CrossRef]

52. Dewulf, J.; Bösch, M.E.; de Meester, B.; van der Vorst, G.; van Langenhove, H.; Hellweg, S.; Huijbregts, M.A.J. Cumulative Exergy Extraction from the Natural Environment (CEENE): A comprehensive Life Cycle Impact Assessment method for resource accounting. Environ. Sci. Technol. 2007, 41, 8477-8483. [CrossRef] [PubMed]

53. Dai, J.; Chen, B.; Sciubba, E. Extended exergy based ecological accounting for the transportation sector in China. Renew. Sustain. Energy Rev. 2014, 32, 229-237. [CrossRef]

54. Sciubba, E. A Thermodynamically Correct Treatment of Externalities with an Exergy-Based Numeraire. Sustainability 2012, 4, 933-957. [CrossRef] 
55. Food and Agriculture Organization of the United Nations. The State of the World Fisheries and Aquaculture 2014: Opportunities and Challenges; Food and Agriculture Organization of the United Nations: Rome, Italy, 2014.

56. Romero, J.C.; Linares, P. Exergy as a global energy sustainability indicator. A review of the state of the art. Renew. Sustain. Energy Rev. 2014, 33, 427-442. [CrossRef]

57. Celpa. Boletim Estatístico; Industria Papeleira Portuguesa: Lisboa, Portugal, 2014.

58. Özilgen, M.; Öner, E.S. Biothermodynamics: Principles and Applications; CRC Press: Boca Raton, FL, USA, 2017.

59. Dewulf, J.; van Langenhove, H.; van de Velde, B. Exergy-Based Efficiency and Renewability Assessment of Biofuel Production. Environ. Sci. Technol. 2005, 39, 3878-3882. [CrossRef] [PubMed]

60. Weight Equivalents: Eggs. Available online: Hannaone.com (accessed on 13 August 2018).

2017 by the authors. Licensee MDPI, Basel, Switzerland. This article is an open access article distributed under the terms and conditions of the Creative Commons Attribution (CC BY) license (http://creativecommons.org/licenses/by/4.0/). 